\title{
Comparison the stresses and deflections of an isotropic and orthotropic rectangular plates with central circular hole under tension load
}

\author{
Ahmed M. Abdullah \\ Assistant Lecturer \\ College of Engineering / University of Mosul
}

\begin{abstract}
The distributions of stresses and deflection in rectangular isotropic and orthotropic plates with central circular hole under transverse static loading have been studied using finite element method. The object of this present work is to analyze the effect of $D / Y$ ratio (where $D$ is hole diameter and $Y$ is plate width) upon stress distribution and deflection in plates under tension subjected to a static loading. The $D / Y$ ratio is varied from $(0.1)$ to $(0.9)$. The results are obtained for four different boundary conditions. The variations of stresses and deflections with respect to $D / Y$ ratio are presented in graphical form. The finite element formulation is carried out by using the analysis section of the ANSYS package
\end{abstract}

Keywords: Finite Element, Isotropic and orthotropic plates, Boundary conditions.

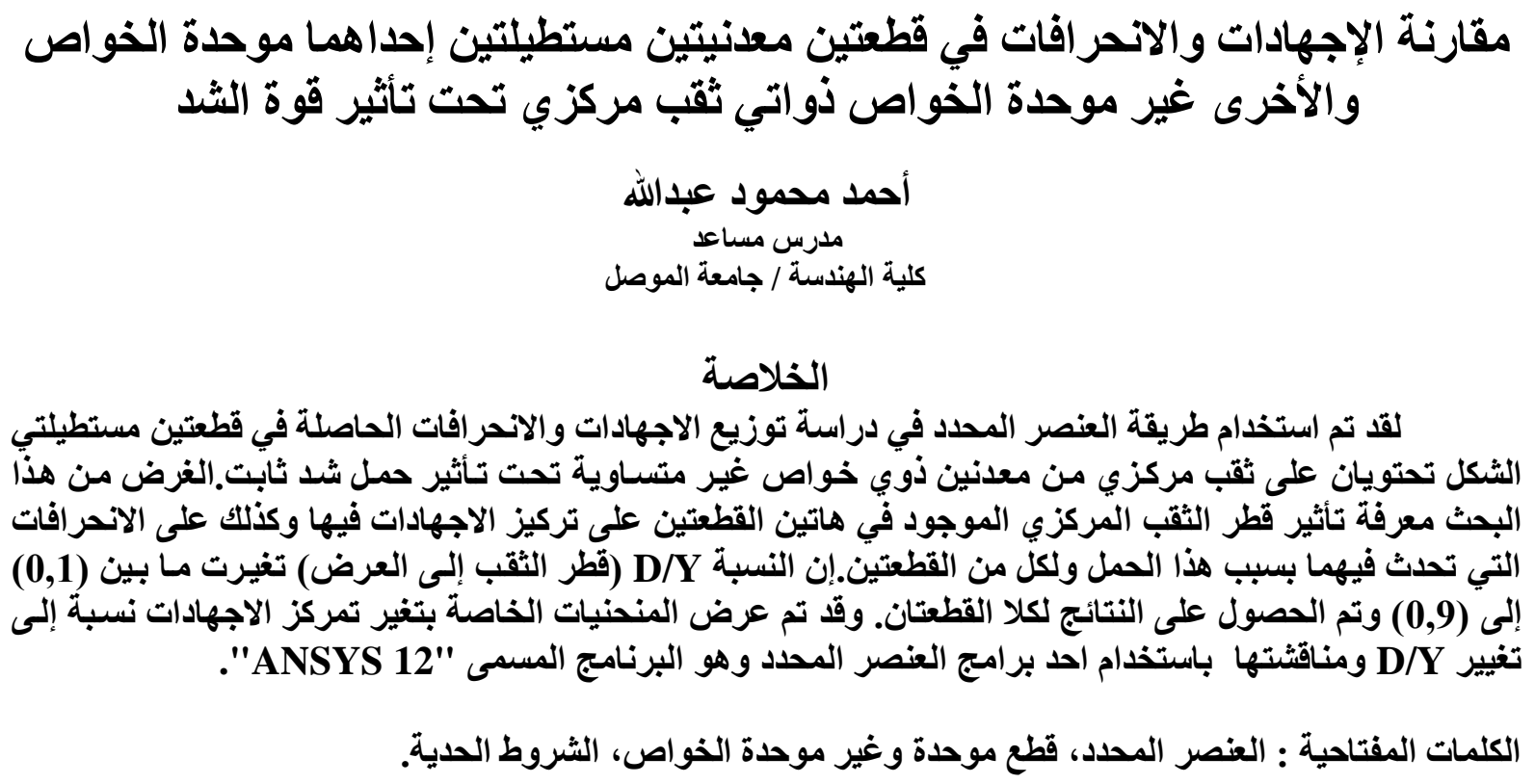




\section{Introduction}

Rectangular isotropic or orthotropic plate with central circular hole under transverse static loading, have found widespread applications in various fields of engineering such as aerospace, marine, automobile and mechanical application. For design of plates with hole, accurate knowledge of deflection, stresses and stress concentration is required. Stress concentration arises from any abrupt change in geometry of plate under loading. As a result, stress distribution is not uniform throughout the cross section. Failures (as we know) such as fatigue cracking and plastic deformation frequently occur at points of stress concentration. $\mathrm{Wu}$ and Cheng [1] considered a circular hole in a laminated composite material under extensional loading. Chen and Hsu [2] studied the stress concentrations around undulating cracks located at the interface of the two materials. Two sets of analytic functions were used for the two materials and the unevenness of the cracks was modeled using perturbation. Wang and Hasebe [3] studied bending of a plate with an inclusion and a crack. Chaudhuri [4] worked on stress concentration around a part through hole weakening a laminated plate by finite element method. Ishikawa and Kohno [5] used this transformation to determine the stresses around square openings and inclusions for plates under in-plane extension. Paul and Rao [6,7] presented a theory for evaluation of stress concentration factor of thick and FRP laminated plate with the help of Lo Christensen-Wu higher order bending theory under transverse loading. Shastry and Raj [8] have analyzed the effect of fiber orientation for a unidirectional composite laminate with finite element method by assuming a plane stress problem under in plane static loading. Xiwu et al. $[9,10]$ evaluated stress concentration of finite composite laminates with elliptical hole and multiple elliptical holes based on classical laminated plate theory. Iwaki [11] worked on stress concentrations in a plate with two unequal circular holes. Ukadgaonker and Rao [12] proposed a general solution for stresses around holes in symmetric laminates by introducing a general form of mapping function and an arbitrary biaxial loading condition in to the boundary conditions. Ting et al. [13] presented a theory for stress analysis by using rhombic array of alternating method for multiple circular holes. Pan et al. (14) developed a 3D boundary element formulation for the analysis of composite laminates with holes. They used a special Green's function, which satisfies the continuity equation between the lamina, and the free surface on the top and bottom faces to convert the problem to a two-dimensional formulation to avoid discretization in the plate thickness direction.

\section{Objectives of this research}

In this work, the effect of $\mathrm{D} / \mathrm{Y}$ ratio on stresses in rectangular isotropic and orthotropic plates under tension load is studied. The purpose of this work is to investigate the effect of $\mathrm{D} / \mathrm{Y}$ ratio on normal stress in $\mathrm{X}, \mathrm{Y}, \mathrm{Z}$ directions $(\sigma \mathrm{x}, \sigma \mathrm{y}, \sigma \mathrm{z})$, shear stress in $\mathrm{XY}, \mathrm{YZ}$, $\mathrm{XZ}$ planes $\left(\tau_{\mathrm{xy}}, \tau_{\mathrm{yz}}, \tau_{\mathrm{xz}}\right)$ and on deflection in all direction. These results for different ratios of $\mathrm{D} / \mathrm{Y}$ are compared for isotropic and orthotropic materials. The results are obtained for four different boundary conditions. The analytical method for such problem is very difficult and hence the finite element method adopt for whole analysis.

\section{Theoretical backgrounds}

Hooke's law for a homogeneous orthotropic plane stress body is [3]

$\varepsilon=[\mathrm{S}]\{\sigma\}$

Where S11, S12, ... \& S66, are elastic compliances. In the absence of body forces, the equilibrium equations are 
$\frac{\partial \sigma_{x}}{\sigma x}+\frac{\partial \tau_{x y}}{\partial y}=0$ and $\frac{\partial \tau_{x y}}{\partial x}+\frac{\partial \sigma_{y}}{\partial y}=0$

Equation (2) can be satisfied by introducing a stress function, $\mathrm{F}(\mathrm{x}, \mathrm{y})$, such that

$$
\sigma_{x}=\frac{\partial^{2} F}{\partial y^{2}}, \sigma_{y}=\frac{\partial^{2} F}{\partial x^{2}} \text { and } \tau_{x y}=-\frac{\partial^{2} F}{\partial x \partial y}
$$

The compatibility equation is

$$
\frac{\partial^{2} \varepsilon_{x}}{\partial y^{2}}+\frac{\partial^{2} \varepsilon_{y}}{\partial x^{2}}=\frac{\partial^{2} \gamma_{x y}}{\partial x \partial y}
$$

Combining equations (1), (3) and (4) gives the compatibility equation in terms of $F$. That equation can be solved using $D_{1} D_{2} D_{3} D_{4} F=0$, where $D_{l}=\left(\left(\frac{\partial}{\partial y}\right)-\mu_{l}\left(\frac{\partial}{\partial x}\right)\right.$ and $\mu_{l}(l=1,2,3,4)$ are the roots of the following characteristic equation [3]:

Thus, $s_{11} \mu^{4}-2 s_{16} \mu^{3}+\left(2 s_{12}+s_{66}\right) \mu^{2}-2 s_{26} \mu+s_{22}=0$

In terms of the complex variables $\mathrm{z}_{1}=\mathrm{x}+\mu_{1} \mathrm{y}$ and $\mathrm{z}_{2}=\mathrm{x}+\mu_{2} \mathrm{y}$, the stresses of equation (3) can be written as [3]

$$
\begin{aligned}
\sigma_{x} & =2 \operatorname{Re}\left[\mu_{1}^{2} \phi^{\prime}\left(z_{1}\right)+\mu_{2}^{2} \psi^{\prime}\left(z_{2}\right)\right], \\
& =2 \operatorname{Re}\left[\mu_{1}^{2} \frac{\phi^{\prime}\left(\zeta_{1}\right)}{\omega_{1}^{\prime}\left(\zeta_{1}\right)}+\mu_{2}^{2} \frac{\psi^{\prime}\left(\zeta_{2}\right)}{\omega_{2}^{\prime}\left(\zeta_{2}\right)}\right], \\
\sigma_{y} & =2 \operatorname{Re}\left[\phi^{\prime}\left(z_{1}\right)+\psi^{\prime}\left(z_{2}\right)\right], \\
& =2 \operatorname{Re}\left[\frac{\phi^{\prime}\left(\zeta_{1}\right)}{\omega_{1}^{\prime}\left(\zeta_{1}\right)}+\frac{\psi^{\prime}\left(\zeta_{2}\right)}{\omega_{2}^{\prime}\left(\zeta_{2}\right)}\right], \\
\sigma_{x y} & =-2 \operatorname{Re}\left[\mu_{1} \phi^{\prime}\left(z_{1}\right)+\mu_{2} \psi^{\prime}\left(z_{2}\right)\right], \\
& =-2 \operatorname{Re}\left[\mu_{1} \frac{\phi^{\prime}\left(\zeta_{1}\right)}{\omega_{1}^{\prime}\left(\zeta_{1}\right)}+\mu_{2} \frac{\psi^{\prime}\left(\zeta_{2}\right)}{\omega_{2}^{\prime}\left(\zeta_{2}\right)}\right]
\end{aligned}
$$

where $\Phi$ and $\psi$ are the complex stress potentials. In the absence of rigid body motions, the displacements are

$$
\begin{aligned}
u & =2 \operatorname{Re}\left[p_{1} \phi^{\prime}\left(z_{1}\right)+p_{2} \psi^{\prime}\left(z_{2}\right)\right], \\
& =2 \operatorname{Re}\left[p_{1} \phi^{\prime}\left(\zeta_{1}\right)+p_{2} \psi^{\prime}\left(\zeta_{2}\right)\right], \\
v & =2 \operatorname{Re}\left[q_{1} \phi^{\prime}\left(z_{1}\right)+q_{2} \psi^{\prime}\left(z_{2}\right)\right], \\
& =2 \operatorname{Re}\left[q_{1} \phi^{\prime}\left(\zeta_{1}\right)+q_{2} \psi^{\prime}\left(\zeta_{2}\right)\right],
\end{aligned}
$$

Where,

$$
\begin{array}{ll}
p_{1}=s_{11} \mu_{1}^{2}+s_{12}-s_{16} \mu_{1}, & p_{2}=s_{11} \mu_{2}^{2}+s_{12}-s_{16} \mu_{2} \quad \text { and } \\
\mathrm{q}_{1}=s_{12} \mu_{1}+\frac{s_{22}}{\mu_{1}}-s_{26} \quad, \mathrm{q}_{2}=s_{12} \mu_{2}+\frac{s_{22}}{\mu_{2}}-s_{26}
\end{array}
$$




\section{Description of Problem:}

To study the influence of $\mathrm{D} / \mathrm{Y}$ ratio upon the deflection and the distribution of different stresses, a rectangular plate of $(200 \mathrm{~mm} * 100 \mathrm{~mm} * 3 \mathrm{~mm})$ in the directions of $\mathrm{X}, \mathrm{Y}, \mathrm{Z}$ respectively with a circular hole of diameter $\mathrm{D}$ at the centre is selected. This plate is exposed to a uniformly distributed static load $\mathrm{P}=(5) \mathrm{N}$ in tension. The results of all cases are analyzed using finite element method. Figure (1) shows the basic model of the problem and its main axes. The $\mathrm{D} / \mathrm{Y}$ ratio is varied from (0.1) to (0.9). Following Table (1). Where; $\mathrm{E}, \mathrm{G}$ and $\mu$ represent modulus of elasticity, modulus of rigidity and Poisson's ratio respectively.

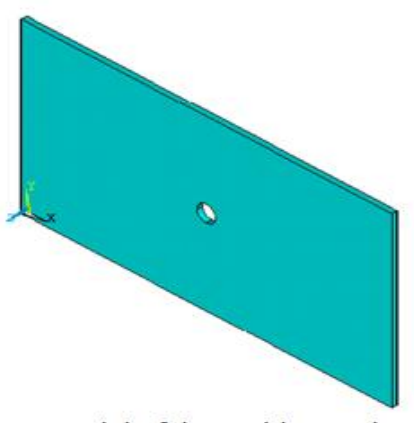

Fig. 1 Basic model of the problem

Table (1): Material properties which are used in the analysis.

\begin{tabular}{|l|c|c|}
\hline Properties & Isotropic & Orthotropic \\
\hline Ex & $225 \mathrm{GPa}$ & $225 \mathrm{GPa}$ \\
\hline $\mathbf{E y}$ & -------------- & $127 \mathrm{GPa}$ \\
\hline $\mathbf{E z}$ & --------------- & $127 \mathrm{GPa}$ \\
\hline $\boldsymbol{\mu x y}$ & -------------- & 0.3 \\
\hline $\boldsymbol{\mu y z}$ & -------------- & 0.3 \\
\hline $\boldsymbol{\mu z x}$ & -------------- & 0.3 \\
\hline Gxy & $37 \mathrm{Gpa}$ & $37 \mathrm{GPa}$ \\
\hline Gyz & -------------- & $37 \mathrm{GPa}$ \\
\hline Gzx & -------------- & $37 \mathrm{GPa}$ \\
\hline
\end{tabular}

\section{Finite Element Analysis}

Twenty nodded Structural 3-D Solid Element (specified as Solid95 in ANSYS package) with element length of $2 \mathrm{~mm}$, is selected based on convergence test and used through out the study. Each node has six degrees of freedom, making a total of 48 degrees of freedom per element. In order to construct the graphical image of the geometries of models for different $\mathrm{D} / \mathrm{Y}$ ratios, rectangular isotropic and orthotropic plates examined using the ANSYS (Advanced Engineering Simulation). Mapped meshing are used for all models so that more elements are employed near the hole boundary. Due to the symmetric nature of different models investigated, it is necessary to discretize the quadrant plate for finite element analysis. Main task in finite element analysis is the selection of the suitable element type. Numbers of checks and convergence test is

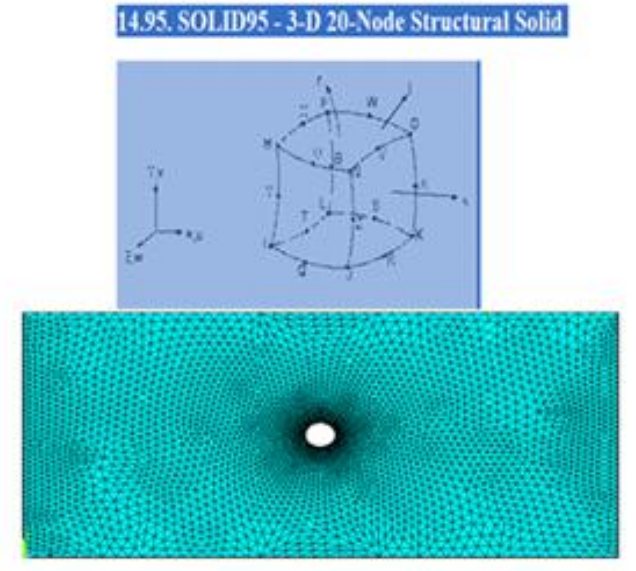

Fig. 2 Typical example of finite element model for $\mathrm{D} / \mathrm{Y}=(0.2)$ made to select of suitable element type from out the different available elements and to decide the element length required. Figure (2) provides the example of the discretized models for $\mathrm{D} / \mathrm{Y}=(0.2)$, used in study. 


\section{ANSYS}

ANSYS finite element analysis software enables engineers to perform the important tasks. Build computer models or transfer computer Aided Drafting

(CAD) models of structures, products, components, or systems. Apply operating loads or other design performance conditions and study the physical responses, such as stress levels, temperature distributions, or the impact of electromagnetic fields. Optimize a design early in the development process to reduce production costs [15].Prototype testing in environments can be done where it otherwise would be undesirable or impossible. The ANSYS program has a comprehensive graphical user interface (GUI) that gives wide facilities, interactive access to program function, commands, documentation, and reference material. The menu system helps users navigate through the ANSYS program. Users can put the required data and by using the mouse and the keyboard or both combinations.

\section{Results and Discussion}

Numerical results are presented for isotropic and orthotropic rectangular plates with a central circular hole. The material properties of different used materials are shown in table (1).Where; E, G and $\mu$ represent modulus of elasticity, modulus of rigidity and Poisson's ratio respectively. Four different plates with different boundary conditions (A), (B), (C) and (D) are tasted. In plate (A) all edges are fixed, in plate (B); two edges are fixed and other two are simply, in plate (C) all edges (in other sides) are fixed and in plate (D); two edges (in other sides) are fixed and other two are simply. Figure (3) provides the boundary conditions at all edges of plates (A), (B), (C) and (D).Stresses and deflections are obtained for uniformly distributed loads $\mathrm{P}=(5) \mathrm{N}$ for all cases and for $(\mathrm{D} / \mathrm{Y})$ ratios from $(0.1)$ to $(0.9)$. The stresses and deflection in all directions for full plate (A), (B), (C) and (D), made of different materials under uniformly distributed load of (5) $\mathrm{N}$ are listed in

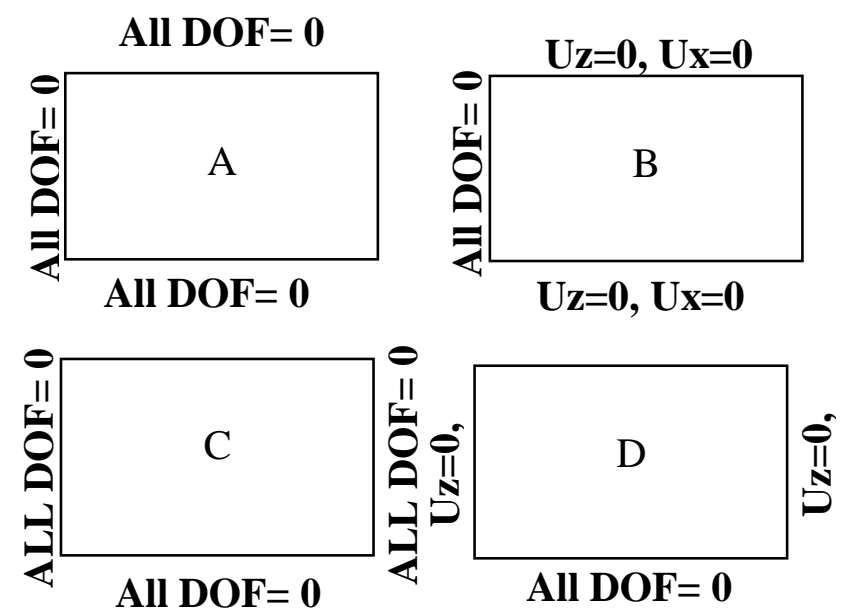

Fig. 3 Boundary conditions for all edges of plates (A), (B), (C) and (D)

Tables (2), show the effect of D/Y ratio on ( $\sigma \mathrm{x}, \sigma \mathrm{y}, \sigma \mathrm{z}, \mathrm{Ux}, \mathrm{Uy}$ and $\mathrm{Uz})$ and ( $\tau_{\mathrm{xy}}, \tau_{\mathrm{yz}}$, $\tau_{\mathrm{xz}}, \sigma_{\mathrm{Von}}$ and Usum) in plates (A), (B), (C) and (D) of full plate (without hole) for isotropic and orthotropic materials.

Tables (2): Stresses and deflection for full plate.

\begin{tabular}{|c|c|c|c|c|c|c|c|c|c|c|c|c|}
\hline $\begin{array}{l}\text { Material } \\
\text { Type }\end{array}$ & Plate & $\begin{array}{c}\sigma x \\
(\mathbf{M P a})\end{array}$ & $\begin{array}{c}\sigma \mathbf{y} \\
(\mathbf{M P a})\end{array}$ & $\begin{array}{c}\sigma \mathbf{\sigma z} \\
(\mathbf{M P a})\end{array}$ & $\begin{array}{c}\mathbf{U x} \\
(\mu \mathrm{m})\end{array}$ & $\begin{array}{c}\mathbf{U y} \\
(\mu \mathrm{m})\end{array}$ & $\begin{array}{c}\mathrm{Uz} \\
(\mu m)\end{array}$ & $\begin{array}{c}\tau \mathbf{x y} \\
(\mathbf{M P a})\end{array}$ & $\begin{array}{c}\tau y z \\
(\mathrm{MPa}) \\
\end{array}$ & $\begin{array}{c}\tau \mathrm{xz} \\
(\mathrm{MPa})\end{array}$ & $\begin{array}{l}\sigma \text { Von } \\
\text { (MPa) }\end{array}$ & $\begin{array}{c}\text { Usum } \\
(\mu \mathrm{m})\end{array}$ \\
\hline \multirow{4}{*}{ Isotropic } & (A) & 2.8 & 1.27 & .240 & .443 & .089 & .008 & 2.15 & .128 & .865 & 5.00 & .443 \\
\hline & (B) & 2.28 & 1.71 & .210 & .507 & .221 & .010 & 1.06 & .168 & .874 & 2.64 & .507 \\
\hline & (C) & .418 & 1.28 & .294 & .053 & .300 & .011 & .872 & .525 & .117 & 2.24 & .301 \\
\hline & (D) & .795 & 1.22 & .311 & .128 & .325 & .302 & .515 & . 446. & .239 & 1.28 & .436 \\
\hline \multirow[t]{4}{*}{ Orthotropic } & (A) & 2.64 & .877 & .192 & .653 & .120 & 011 & 1.40 & .101 & .775 & 3.71 & .654 \\
\hline & (B) & 2.64 & 1.26 & .171 & .718 & .322 & .014 & .845 & .125 & .782 & 2.72 & .718 \\
\hline & (C) & .613 & 1.29 & 261 & .076 & .597 & .917 & .755 & .498 & .120 & 3.05 & 1.09 \\
\hline & (D) & 1.02 & 1.27 & .277 & .196 & .643 & 1.49 & .562 & .494 & .066 & 1.41 & 1.62 \\
\hline
\end{tabular}


In figures $(4,5)$ when there is no hole in the piece, (plate A), note that when Isotropic is used the value of Von Mises stress is not more than (5) MPa but (under the same conditions) on the other hand when Orthotropic is used the stress will be (3.71) MPa. In figures $(6,7)$, when $(\mathrm{D} / \mathrm{Y}=0.5)$ it can be noticed that the value of Von Mises stress changed from $(5.18)$ to $(4.23) \mathrm{MPa}$, whereas in figures $(8,9)$ at $(\mathrm{D} / \mathrm{Y}=0.9)$ the value of Von Mises stress decreased from (5.82) to (4.87) MPa.

In figures $(10,11)$, (plate A) with no hole in the piece, the value of deflection for Isotropic, the value of Displacement vector sum (Usum) is not more than $(0.443) \mu \mathrm{m}$, but (under the same conditions) in the case of using Orthotropic will be (.654) $\mu \mathrm{m}$. Where as in figures $(12,13)$ at $(\mathrm{D} / \mathrm{Y}=0.9)$ the value of displacement vector sum (Usum) increased from (.553) to $(1.05) \mu \mathrm{m}$.

In figures $(14,15)$ (plate $C$ ) with no hole in the piece, the value of deflection for Isotropic, is used, the value of Von Mises stress is not more than (2.24) Mpa, but (under the same conditions) in the case of using Orthotropic will be (3.05) Mpa. Whereas in figures (16, $17)$ at $(\mathrm{D} / \mathrm{Y}=0.9)$ value of Von Mises stress increased from(10.9)to (12.4) MPa.

In figures $(18,19)$ (plate $C$ ) with no hole in the piece, the value of deflection for Isotropic is used, the value of displacement vector sum (Usum) is not more than $(0.301) \mu \mathrm{m}$. However (under the same conditions) in the case of Orthotropic will be (1.09) $\mu \mathrm{m}$, whereas in figures $(20,21)$ at $(\mathrm{D} / \mathrm{Y}=0.9)$ the value of Displacement vector sum (Usum) increased from (3.57) to $(5.45) \mu \mathrm{m}$.

In figure (22) we see that the variation of $\boldsymbol{\sigma x}$ with respect to $\mathrm{D} / \mathrm{Y}$ ratio is remained constant approximately at (2.8) $\mathrm{MPa}$. In case of plate (A) it is decreased to (2.4) $\mathrm{MPa}$ at max. $\mathrm{D} / \mathrm{Y}$ for isotropic but for orthotropic plate it can be noticed that $\boldsymbol{\sigma x}$ is about (2.64) MPa firstly then increased to reach a max. Value (3.8) $\mathrm{MPa}$ at $\mathrm{D} / \mathrm{Y}=0.7$ and finally decreased to (2.8) $\mathrm{MPa}$ at max. D/Y. In the case (B) it is observed that $\sigma \mathrm{x}$ is about (2.28) MPa firstly for isotropic and (2.64) $\mathrm{MPa}$ for orthotropic, after that it is increased to reach a max. value (2.6) $\mathrm{MPa}$ for isotropic and (4.5) for orthotropic at $\mathrm{D} / \mathrm{Y}=0.9$. In the case of plate $(\mathrm{C}) ; \boldsymbol{\sigma x}$ increased from (.418) and (.613) $\mathrm{MPa}$ to (10) and (12) MPa for isotropic and orthotropic plates respectively with increasing of $\mathrm{D} / \mathrm{Y}$ ratio to 0.9 . In the case of plate (D); $\boldsymbol{\sigma x}$ increased from(.795 )and(1.02) $\mathrm{MPa}$ to(10.5) and(12.5) $\mathrm{MPa}$ for isotropic and orthotropic plates respectively with increase of $\mathrm{D} / \mathrm{Y}$ ratio to 0.9 .

In figure (23), the following observations can be made from these results. It can be noticed that the variation of $\boldsymbol{\sigma y}$ with respect to $\mathrm{D} / \mathrm{Y}$ ratio is observed: the maximum for isotropic plate in the case of plate (C), maximum for both in the case of plate (D), maximum for orthotropic plate in the case of plate (B), and almost negligible in the case of plate (A). In the case of plate (A); $\boldsymbol{\sigma y}$ increased from (1.27) and (0.877) MPa to (1.65) and (1.55) MPa with increasing of $\mathrm{D} / \mathrm{Y}$ ratio to 0.9 for isotropic and orthotropic plates respectively. In case of plate (B); $\boldsymbol{\sigma y}$ increased from (1.71) and (1.26) MPa to (3.55) MPa for both with increase of $\mathrm{D} / \mathrm{Y}$ ratio to 0.9. In case of plate $(\mathrm{C}) ; \boldsymbol{\sigma y}$ increased from (1.28) and (1.29) $\mathrm{MPa}$ to (4.0) and (3.1) $\mathrm{MPa}$ with increasing of $\mathrm{D} / \mathrm{Y}$ ratio to 0.9 for isotropic and orthotropic plates respectively. In case of plate (D); $\boldsymbol{\sigma y}$ increased from (1.22) and (1.27) MPa to (4.02) and (4.08) MPa with increase of $\mathrm{D} / \mathrm{Y}$ ratio to 0.9 for isotropic and orthotropic plates respectively.

Figure (24) shows the following observations. It can be noticed that the variation of $\boldsymbol{\sigma z}$ with respect to $\mathrm{D} / \mathrm{Y}$ ratio is observed, maximum in the case of plates (C) and (D) for isotropic plates and significant in plates (A) and (B). In plate (A); $\boldsymbol{\sigma z}$ increased from (.24) and (.192) $\mathrm{MPa}$, to (.41) and (.321) $\mathrm{MPa}$, with $\mathrm{D} / \mathrm{Y}=0.2$, and decreased to (.335) and (.269) $\mathrm{MPa}$, with increase of $\mathrm{D} / \mathrm{Y}$ ratio from 0.2 to 0.5 , and again increased to (.393) and (.314) 
Abdulla: Comparison the stresses and deflections of an isotropic and orthotropic

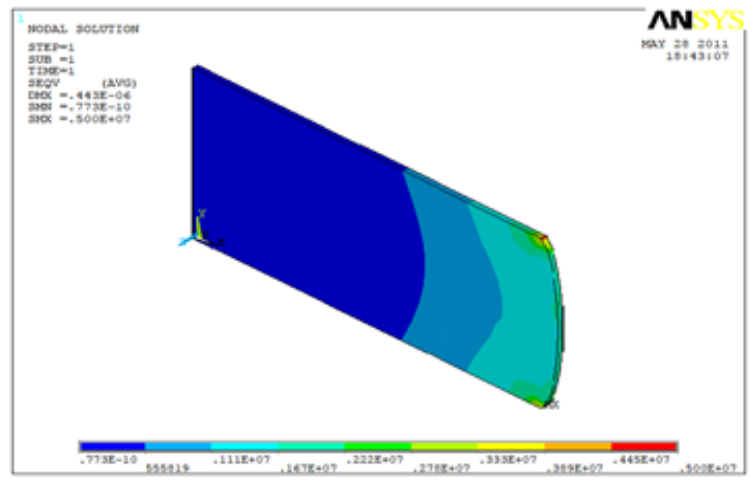

Fig. 4 Stress distribution(Von Mises stresses) for isotropic material (without hole)

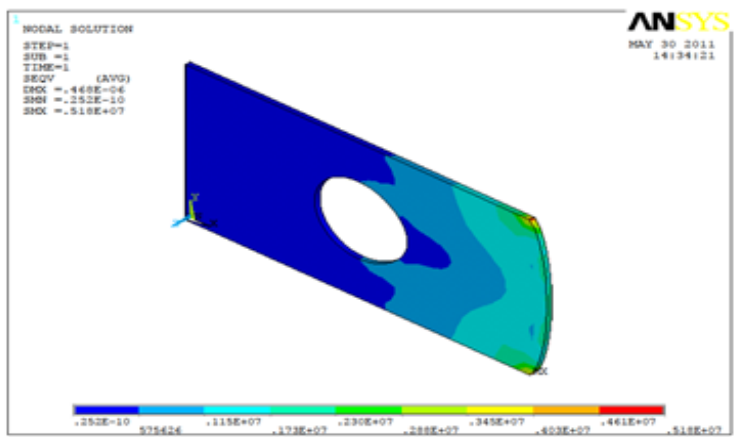

Fig. 6 Stress distribution(Von Mises stresses) for isotropic material (with $\mathrm{D} / \mathrm{Y}$ ratio $=0.5$ )

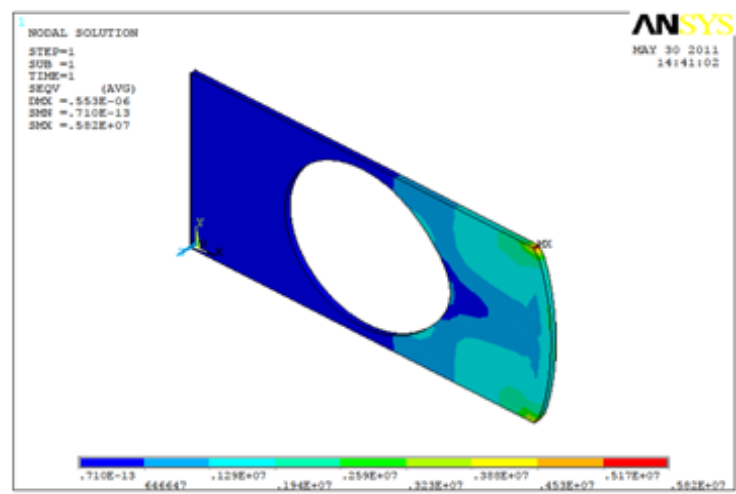

Fig. 8 Stress distribution(Von Mises stresses) for isotropic material (with $\mathrm{D} / \mathrm{Y}$ ratio $=0.9$ )

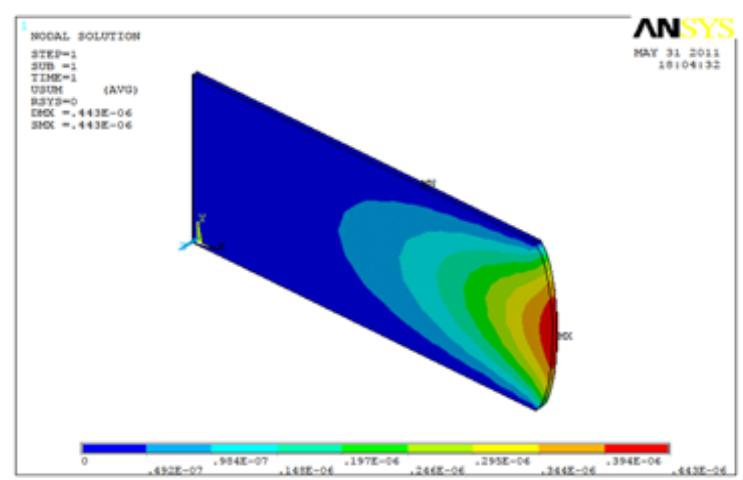

Fig. 10 Deflection distribution (USUM ) for isotropic material (without hole)

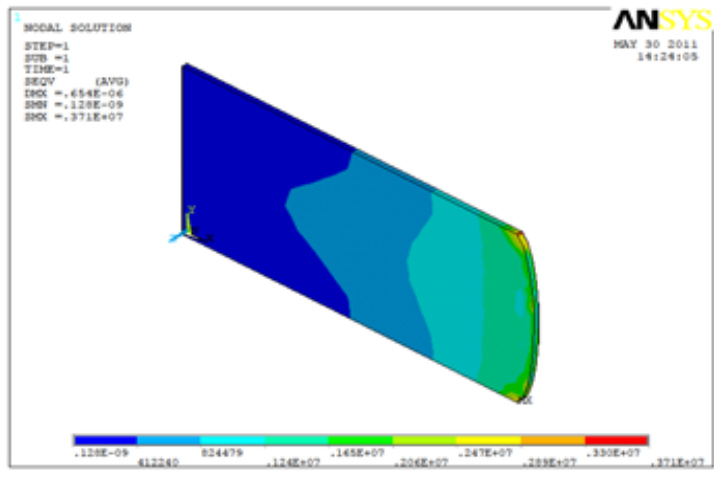

Fig. 5 Stress distribution(Von Mises stresses) for orthotropic material (without hole)

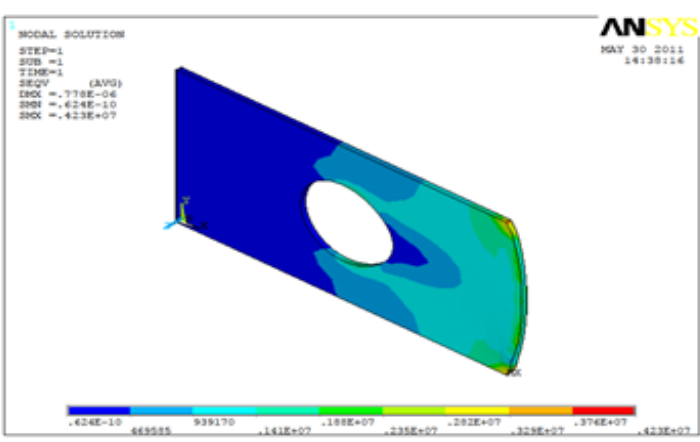

Fig. 7 Stress distribution (Von Mises stresses) for orthotropic material (with $\mathrm{D} / \mathrm{Y}$ ratio $=0.5$ )

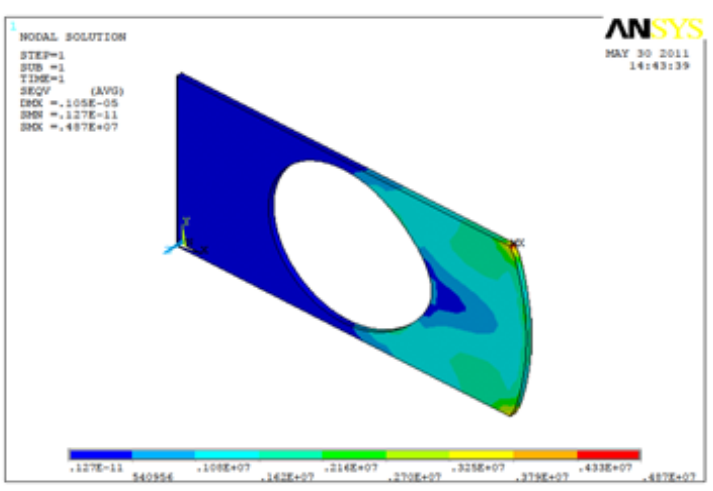

Fig. 9 Stress distribution (Von Mises stresses) for orthotropic material (with $\mathrm{D} / \mathrm{Y}$ ratio $=0.9$ )

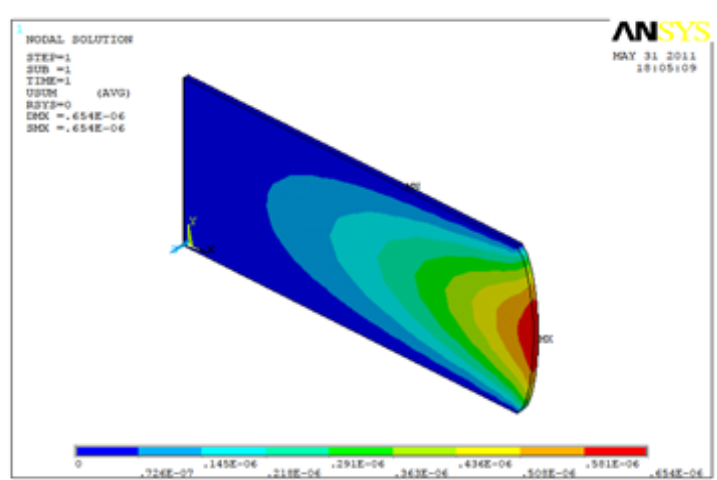

Fig. 11 Deflection distribution (USUM ) for orthotropic material (without hole) 


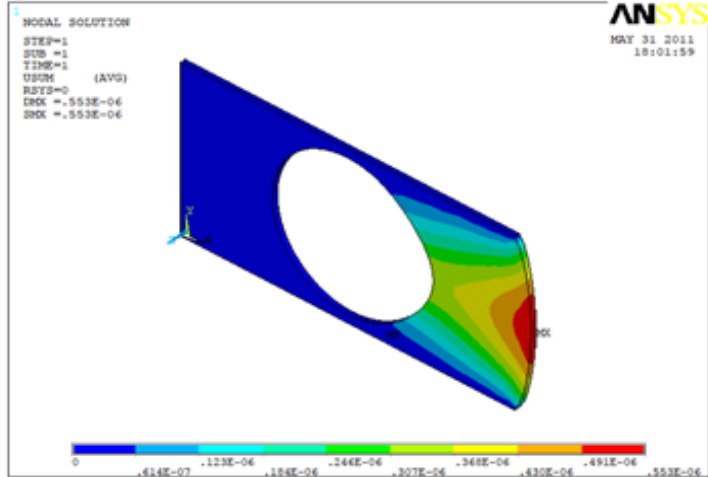

Fig. 12 Deflection distribution (UsUM) for isotropic material (with $\mathrm{D} / \mathrm{Y}$ ratio $=0.9$ )

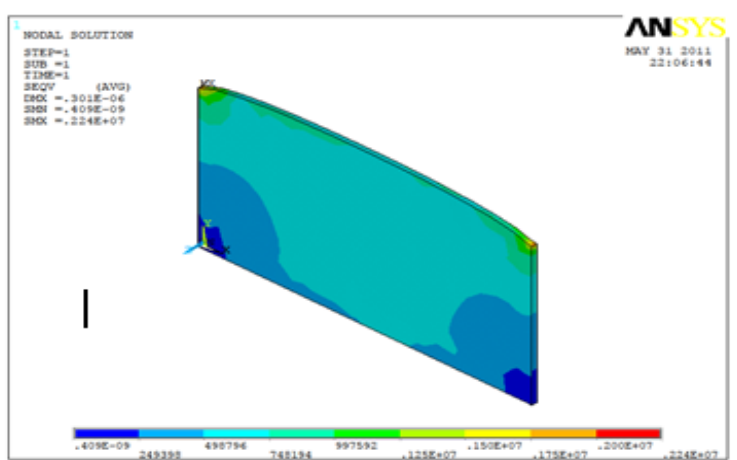

Fig. 14 Stress distribution (Von Mises stress) for isotropic material (without hole) (Horizontal case)

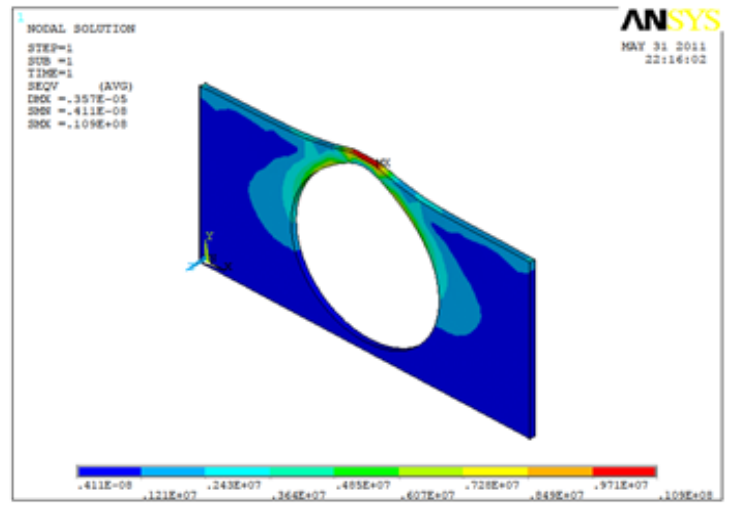

Fig. 16 Stress distribution (Von Mises stress) for isotropic material $($ with $\mathrm{D} / \mathrm{Y}$ ratio $=0.9)$ (Horizontal case)

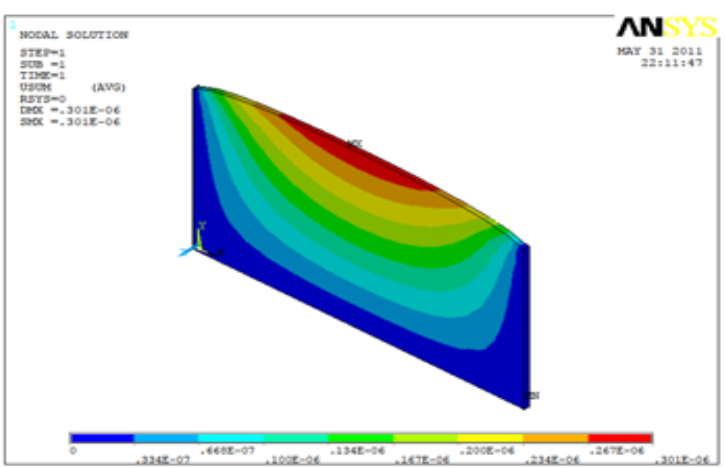

Fig. 18 Deflection distribution (USUM ) for isotropic material (without hole) (Horizontal case)

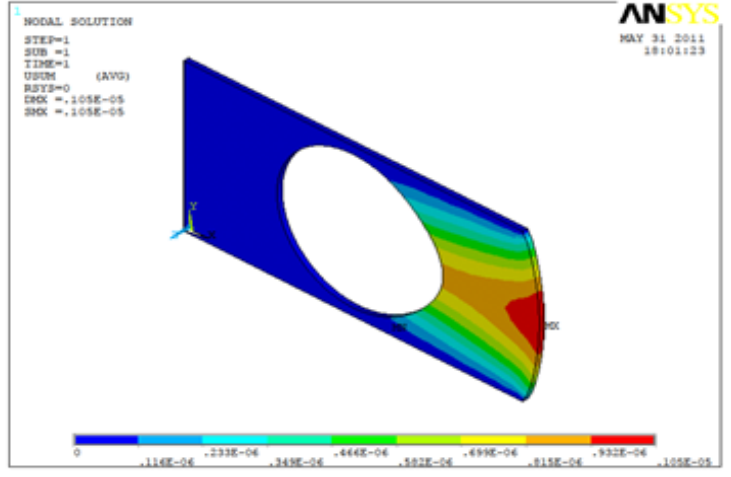

Fig.13 Deflection distribution (UsUM) for orthotropic material (with $\mathrm{D} / \mathrm{Y}$ ratio $=0.9$ )

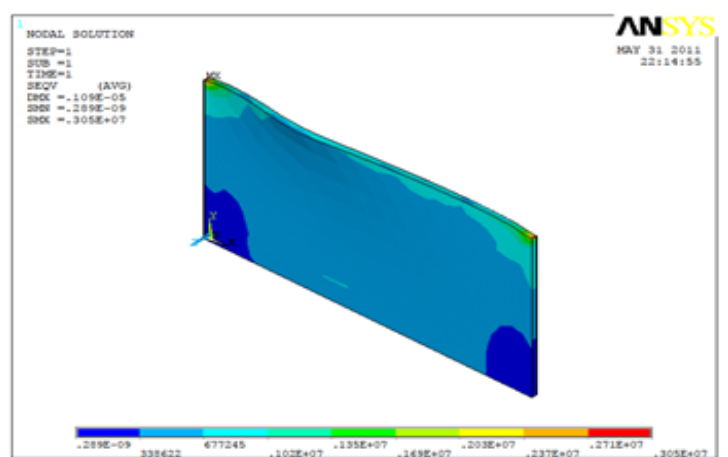

Fig. 15 Stress distribution (Von Mises stress) for orthotropic material (without hole)

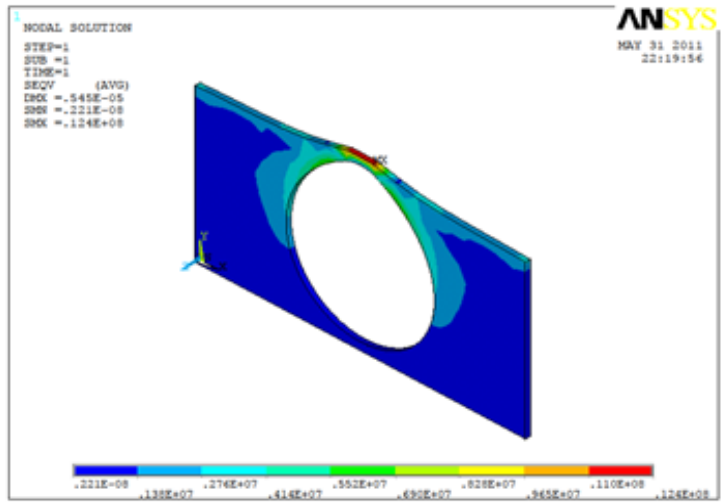

Fig. 17 Stress distribution (Von Mises stress) for orthotropic material (with $\mathrm{D} / \mathrm{Y}$ ratio $=0.9$ ) (Horizontal case)

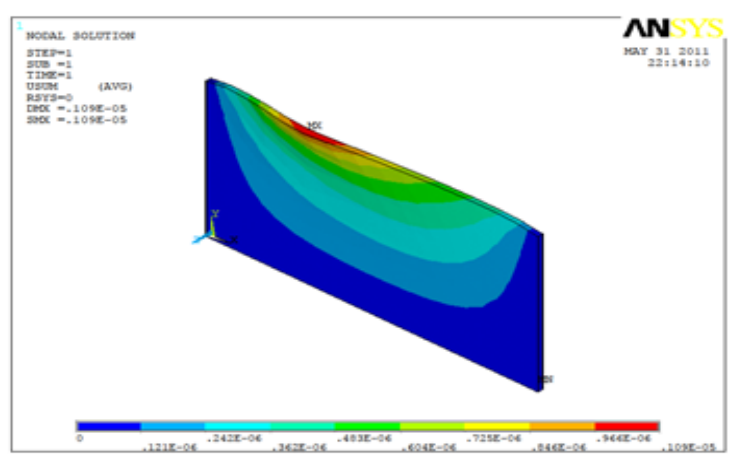

Fig. 19 Deflection distribution (USUM ) for orthotropic material (without hole) (Horizontal case) 
Abdulla: Comparison the stresses and deflections of an isotropic and orthotropic

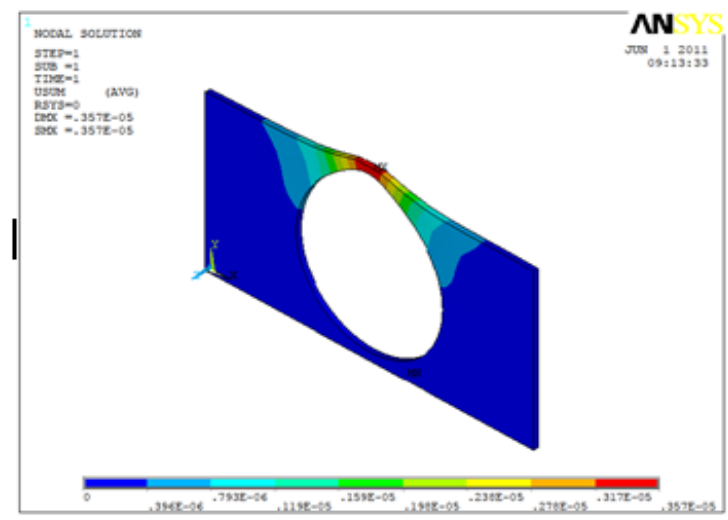

Fig. 20 Deflection distribution (USUM) for isotropic material (with $\mathrm{D} / \mathrm{Y}$ ratio $=0.9$ ) (Horizontal case)
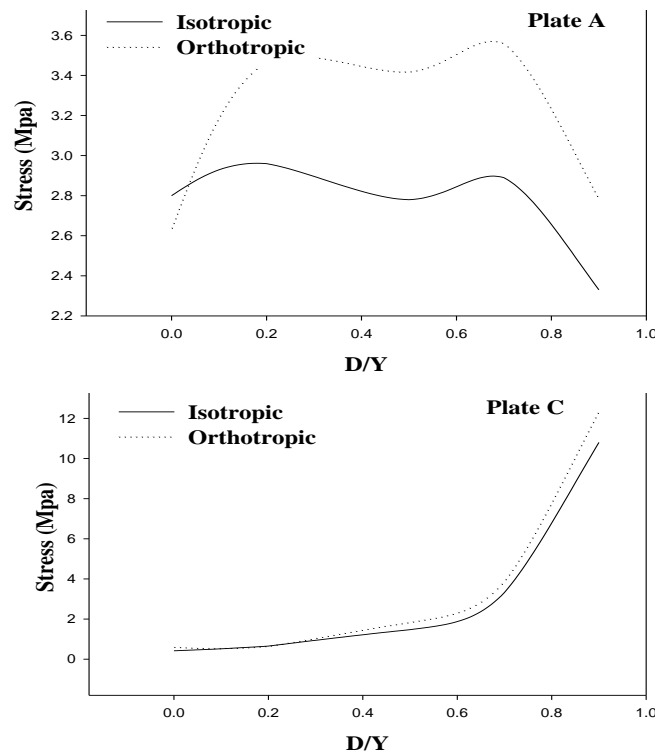

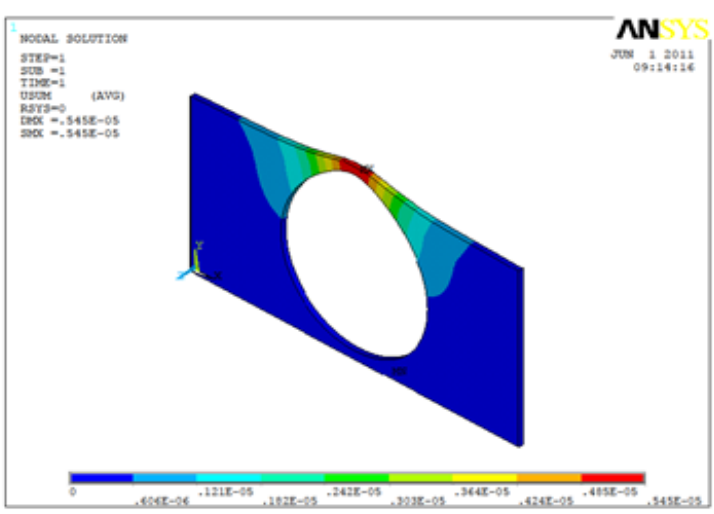

Fig. 21 Deflection distribution (USUM) for orthotropic material $($ with $\mathrm{D} / \mathrm{Y}$ ratio $=0.9$ ) (Horizontal case)
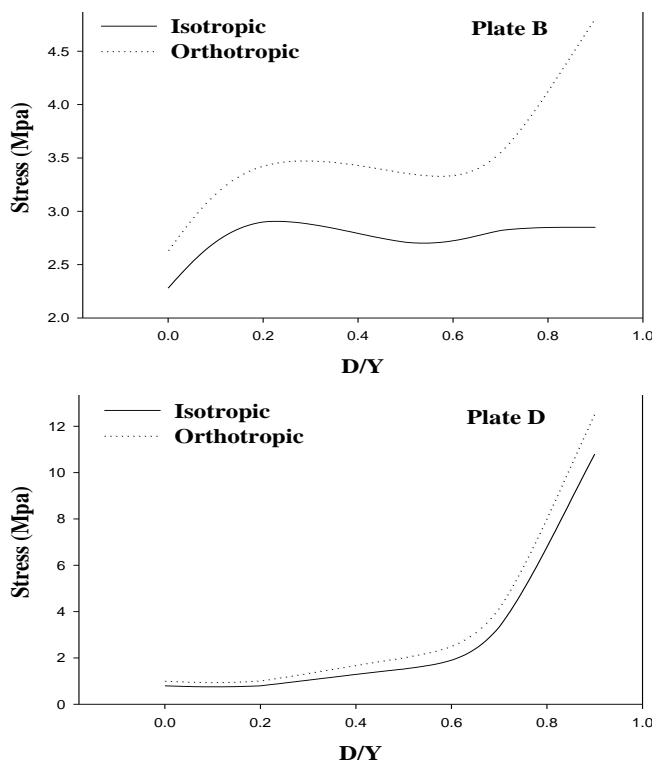

Fig.22 Effect of hole diameter on $\boldsymbol{\sigma x}$ in plates (A), (B), (C) and (D) of an isotropic and orthotropic materials
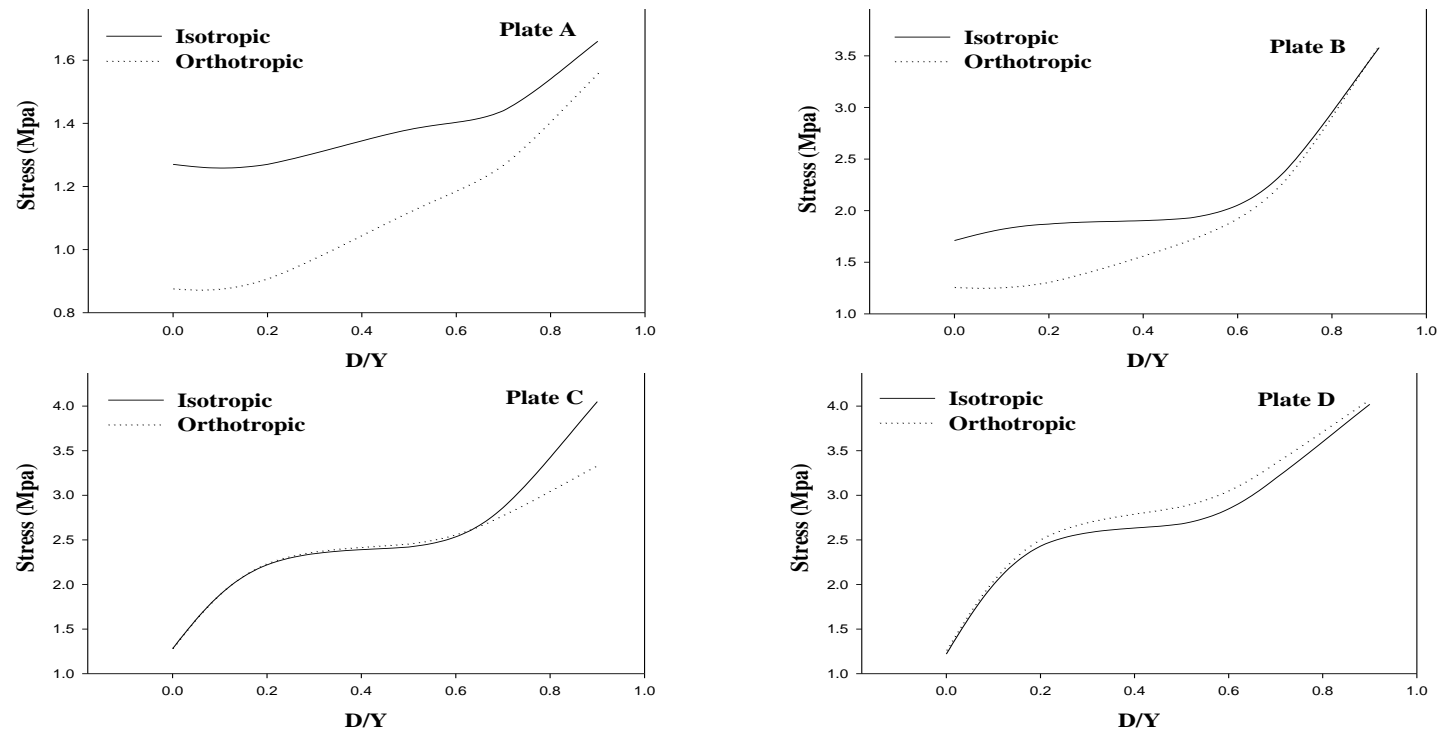

Fig. 23 Effect of hole diameter on $\boldsymbol{\sigma y}$ in plates (A), (B), (C) and (D) of an isotropic and orthotropic materials 

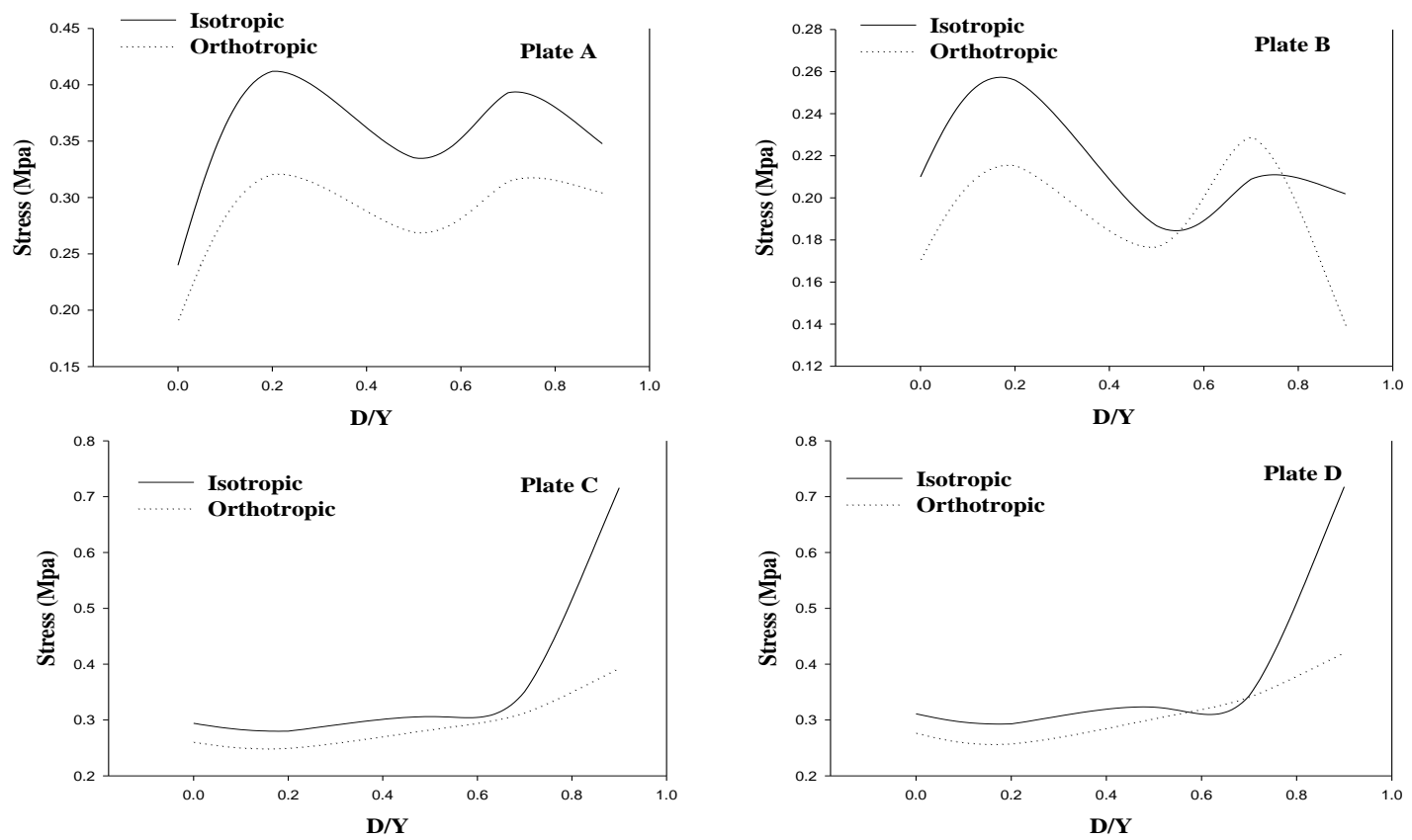

Fig. 24 Effect of hole diameter on $\boldsymbol{\sigma z}$ in plates (A), (B), (C) and (D) of an isotropic and orthotropic materials

increase of $\mathrm{D} / \mathrm{Y}$ ratio from 0.7 to 0.9 for isotropic and orthotropic plates respectively. In the case of plate (B); $\boldsymbol{\sigma z}$ increased from (.21) and (.171) MPa to (.256) and (.215) MPa with increase of $\mathrm{D} / \mathrm{Y}$ ratio from 0.5 to 0.7 , and again decreased to (.347) and (.304) MPa, with $\mathrm{D} / \mathrm{Y}=0.2$, decreased to (.186) and (.176) $\mathrm{MPa}$ with increase of $\mathrm{D} / \mathrm{Y}$ ratio from 0.2 to 0.5 . Again increased to (.208) and (.229) MPa with increase of $\mathrm{D} / \mathrm{Y}$ ratio from 0.5 to 0.7 and again decreased to (.201) and (.139) $\mathrm{MPa}$ with increase of $\mathrm{D} / \mathrm{Y}$ ratio from 0.7 to 0.9 for isotropic and orthotropic plates respectively. In the case of plate (C); $\boldsymbol{\sigma z}$ increased from (.294) and (.261) MPa to (0.715) and (0.393) MPa with increase of D/Y ratio to 0.9 for isotropic and orthotropic plates respectively. In the case of plate (D); $\boldsymbol{\sigma Z}$ remained constant (for isotropic plate) approximately at (0.3) MPa until $\mathrm{D} / \mathrm{Y}=0.7$, then increased to (7.25) MPa, whereas it increased from (.277) to (.41) $\mathrm{MPa}$ with increase of $\mathrm{D} / \mathrm{Y}$ ratio to 0.9 for orthotropic plate.

Figure (25) shows the following observations from these results. It can be noticed that the variation of $\sigma_{\text {Von }}$ with respect to $\mathrm{D} / \mathrm{Y}$ ratio is observed, maximum in the case of plates (C) and (D) and significant in the plates (A) and (B) for both plates. In the case of plate (A); $\boldsymbol{\sigma}_{\text {Von }}$ increased from (5.0) and (3.7) MPa to (5.82) and (4.87) $\mathrm{MPa}$ with increase of D/Y ratio to 0.9 for isotropic and orthotropic plates respectively. In the case of plate (B); $\boldsymbol{\sigma}_{\mathbf{V}}$ increased from (2.64) and (2.72) MPa to (3.66) and (3.69) MPa with $\mathrm{D} / \mathrm{Y}=0.2$, decreased to (3.46) and (3.58) $\mathrm{MPa}$ with increase of $\mathrm{D} / \mathrm{Y}$ ratio from 0.2 to 0.5 and again increased to (4.52) and (4.81) $\mathrm{MPa}$ when $\mathrm{D} / \mathrm{Y}=0.9$ for isotropic and orthotropic plates respectively. In the case (C) ; $\boldsymbol{\sigma}_{\mathbf{V} o n}$ increased from (2.24) and (3.05) MPa to (3.31) and (3.71) MPa with increase of $\mathrm{D} / \mathrm{Y}$ ratio to 0.7 , then increased to (10.9) and (12.4) $\mathrm{MPa}$ when $\mathrm{D} / \mathrm{Y}=0.9$ for isotropic and orthotropic plates respectively. In the case of plate (D); $\boldsymbol{\sigma}_{\mathbf{V o n}}$ increased from (1.28) and (1.41) $\mathrm{MPa}$ to (10.9) and (12.6) $\mathrm{MPa}$ with increase of $\mathrm{D} / \mathrm{Y}$ ratio to 0.9 for isotropic and orthotropic plates respectively.

Figure (26) shows the following observations from these results. It can be noticed that the variation of $\mathbf{U x}$ with respect to $\mathrm{D} / \mathrm{Y}$ ratio is observed. The maximum for both plates in the case of plate (C), and maximum for orthotropic plate, and significant for isotropic plate in the case of plate (B), and significant for orthotropic plates in the case of plates (A) and (B), 
and almost negligible for isotropic plates in the case of plates (A) and (B). In the case of plate (A); $\mathbf{U x}$ increased from (.443) and (.653) $\mu \mathrm{m}$ to (.552) and (1.05) $\mu \mathrm{m}$ with increased of $\mathrm{D} / \mathrm{Y}$ ratio to 0.9 for isotropic and orthotropic plates respectively. In the case of plate (B); $\mathbf{U x}$ increased from (.507) and (.718) $\mu \mathrm{m}$ to (.983) and (1.68) $\mu \mathrm{m}$ with increased of D/Y ratio to 0.9 for isotropic and orthotropic plates respectively. In case of plate (C); $\mathbf{U x}$ increased from (.053) and (.076) $\mu \mathrm{m}$ to (.579) and (.70) $\mu \mathrm{m}$ with increased of $\mathrm{D} / \mathrm{Y}$ ratio to 0.9 for isotropic and orthotropic plates respectively. In the case of plate (D); $\mathbf{U x}$ increased from (.128) and $(.196) \mu \mathrm{m}$ to $(.577)$ and $(.695) \mu \mathrm{m}$ with increase of $\mathrm{D} / \mathrm{Y}$ ratio to 0.9 for isotropic and orthotropic plates respectively.

Figure (27) shows the following observations from these results. It can be noticed that the variation of $\mathbf{U y}$ with respect to $\mathrm{D} / \mathrm{Y}$ ratio is observed, maximum for both plate in the case of plates (C), and (D), and significant for both plates in the case of plate (B), and almost negligible for both plates in the case of plate (A). In the case of plate (A); $\mathbf{U y}$ increased from (.089) and (.12) $\mu \mathrm{m}$ to (.118) and (.209) $\mu \mathrm{m}$ with increase of $\mathrm{D} / \mathrm{Y}$ ratio to 0.9 for isotropic and orthotropic plates respectively. In the case of plate (B); $\mathbf{U y}$ increased from (.221) and (.322) $\mu \mathrm{m}$ to (.778) and (1.53) $\mu \mathrm{m}$ with increase of $\mathrm{D} / \mathrm{Y}$ ratio to 0.9 for isotropic and orthotropic plates respectively. In the case of plate (C); $\mathbf{U y}$ increased from (0.3) and (0.597) $\mu \mathrm{m}$ to (3.56) and (5.45) $\mu \mathrm{m}$ with increase of $\mathrm{D} / \mathrm{Y}$ ratio to 0.9 for isotropic and orthotropic plates respectively. In the case of plate (D); $\mathbf{U y}$ increased from (.325) and (.643) $\mu \mathrm{m}$ to (3.72) and $(6.12) \mu \mathrm{m}$ with increase of $\mathrm{D} / \mathrm{Y}$ ratio to 0.9 for isotropic and orthotropic plates respectively.

Figure (28) shows the following observations from these results. It can be noticed that the variation of $\mathbf{U z}$ with respect to $\mathrm{D} / \mathrm{Y}$ ratio is observed, maximum for both plates in the case of plates (C), and (D), minimum for both plates in the case of (B), and significant for orthotropic plate, but negligible for isotropic plate in the case of plate (A). In the case of plate (A); $\mathbf{U z}$ increased for orthotropic plate from (.013) to (.676) $\mu \mathrm{m}$ when $\mathrm{D} / \mathrm{Y}=0.2$, then decreased to $(.015) \mu \mathrm{m}$, whereas it for isotropic plate approximately remained constant at (.01) $\mu \mathrm{m}$. In the case of plate (B); $\mathbf{U z}$ increased from (.01) and (.014) $\mu \mathrm{m}$ to (.215) and (.259) $\mu \mathrm{m}$ with $\mathrm{D} / \mathrm{Y}=0.2$, then decreased to (.011) and (.021) $\mu \mathrm{m}$ with increase of $\mathrm{D} / \mathrm{Y}$ ratio from 0.2 to 0.7 and again increased to (.013) and (.023) $\mu \mathrm{m}$ when $\mathrm{D} / \mathrm{Y}=0.9$ for isotropic and orthotropic plates respectively. In the case of plate (C); $\mathbf{U z}$ increased from (.301) and (1.09) $\mu \mathrm{m}$ to (3.57) and (5.45) $\mu \mathrm{m}$ with increase of $\mathrm{D} / \mathrm{Y}$ ratio to 0.9 for isotropic and orthotropic plates respectively. In the case of plate (D); $\mathbf{U z}$ decreased from (.302) and (.215) $\mu \mathrm{m}$ to (.010) and (.015) $\mu \mathrm{m}$ with $\mathrm{D} / \mathrm{Y}=0.7$, then increased to (.028) and (.045) $\mu \mathrm{m}$ with increase of $\mathrm{D} / \mathrm{Y}$ ratio from 0.7 to 0.9 for isotropic and orthotropic plates respectively.

Figure (29) shows the following observations from these results. It can be noticed that the variation of Usum with respect to $\mathrm{D} / \mathrm{Y}$ ratio is maximum for both plates in the case of plates (C), and (D), and significant for orthotropic plates in the case of plates (A) and (B), and almost negligible for isotropic plates in the case of plates (A) and (B). In the case of plate (A); Usum increased from (.443) and (.654) $\mu \mathrm{m}$ to (.553) and (1.05) $\mu \mathrm{m}$ with increase of D/Y ratio to 0.9 for isotropic and orthotropic plates respectively. In the case of plate (B); Usum increased from (.507) and (.718) $\mu \mathrm{m}$ to (.984) and (1.86) $\mu \mathrm{m}$ with increase of $\mathrm{D} / \mathrm{Y}$ ratio to 0.9 for isotropic and orthotropic plates respectively. In the case of plate (C); Usum increased for isotropic plate from (.306) to (.405) $\mu \mathrm{m}$. It decrease for orthotropic plate from (1.09) to (.636) $\mu \mathrm{m}$, when $\mathrm{D} / \mathrm{Y}=0.2$, then increased for both plate from (.405) and (.636) to (3.57) and (5.45) $\mu \mathrm{m}$ with increase of $\mathrm{D} / \mathrm{Y}$ ratio from 0.2 to 0.9 for isotropic and orthotropic plates respectively. In the case of plate (D); Usum increased for isotropic plate from (.436) to (.467) $\mu \mathrm{m}$. It decrease for orthotropic plate from (1.62) to (.68) $\mu \mathrm{m}$ when $\mathrm{D} / \mathrm{Y}=0.2$, then increased 
for both plate from (.467) and (.68) to (3.72) and (6.12) $\mu \mathrm{m}$ with increase of D/Y ratio from 0.2 to 0.9 for isotropic and orthotropic plates respectively.

Figure (30), cases of plate, the variation of $\boldsymbol{\tau}_{\mathbf{y z}}$ with respect to $\mathrm{D} / \mathrm{Y}$ ratio is negligible in the four cases of plates, the variation of $\boldsymbol{\tau}_{\mathbf{x z}}$ with respect to $\mathrm{D} / \mathrm{Y}$ ratio is observed, significant in case of plate (A), maximum in the case of plate (B) and negligible in the cases of (C) and (D). In the case (A) the value of $\boldsymbol{\tau}_{\mathbf{x y}}$, increased from (2.17) to (2.64) MPa, and $\boldsymbol{\tau}_{\mathbf{y z}}$ increased from (.128) to (.212) $\mathrm{MPa}$, with increase of $\mathrm{D} / \mathrm{Y}$ ratio to 0.9 . And $\boldsymbol{\tau}_{\mathbf{x z}}$ increased from (.888) to (1.27) $\mathrm{MPa}$, when $\mathrm{D} / \mathrm{Y}=0.2$, then decreased to (1.2) $\mathrm{MPa}$ with increase of $\mathrm{D} / \mathrm{Y}$ ratio from 0.2 to 0.5 , then, increased to (1.24) $\mathrm{MPa}$ with increase of $\mathrm{D} / \mathrm{Y}$ ratio from 0.5 to 0.7 , and finally decreased to (.966) $\mathrm{MPa}$, with increase of $\mathrm{D} / \mathrm{Y}$ ratio from 0.7 to 0.9 . In the case (B) the value of $\boldsymbol{\tau}_{\mathbf{x y}}$ increased from (1.09) to (1.6) MPa, and $\boldsymbol{\tau}_{\mathbf{y z}}$ increased from (.174) to (.334), when $\mathrm{D} / \mathrm{Y}=0.2$. Then decreased to (.19) $\mathrm{MPa}$ with increase of $\mathrm{D} / \mathrm{Y}$ ratio from 0.2 to 0.9. And $\tau_{\mathbf{x z}}$ increased from (.902) to (1.29) $\mathrm{MPa}$, when $\mathrm{D} / \mathrm{Y}=0.2$, then decreased to (1.23) $\mathrm{MPa}$, with increase of $\mathrm{D} / \mathrm{Y}$ ratio from 0.2 to 0.5 . Then increased to (1.27) $\mathrm{MPa}$ with increase of $\mathrm{D} / \mathrm{Y}$ ratio from 0.5 to 0.7 , and decreased to (.984) MPa with increase of $\mathrm{D} / \mathrm{Y}$ ratio from 0.7 to 0.9 . In the case (C) the value of $\tau_{\mathbf{x y}}$ increased from (.872) to (3.69) $\mathrm{MPa}$, with increase of $\mathrm{D} / \mathrm{Y}$ ratio to 0.9 . And $\tau_{\mathrm{yz}}$ decreased from $(.525)$ to (.445) $\mathrm{MPa}$ when $\mathrm{D} / \mathrm{Y}=0.2$, then increased to (.663) $\mathrm{MPa}$ with increase of $\mathrm{D} / \mathrm{Y}$ ratio from 0.2 to 0.7 . And finally decreased to (.651) $\mathrm{MPa}$ with increase of $\mathrm{D} / \mathrm{Y}$ ratio from 0.7 to 0.9 , and $\boldsymbol{\tau}_{\mathbf{x z}}$ increased from (.154) to (.439) $\mathrm{MPa}$ when $\mathrm{D} / \mathrm{Y}=0.5$, then decreased to (.14) MPa with increase of $\mathrm{D} / \mathrm{Y}$ ratio from 0.5 to 0.9 , then increased to (.327) $\mathrm{MPa}$ with increase of $\mathrm{D} / \mathrm{Y}$ ratio from 0.7 to 0.9 . In the case (D) the value of $\boldsymbol{\tau}_{\mathbf{x y}}$ increased from (.515) to (3.55) $\mathrm{MPa}$, with increase of $\mathrm{D} / \mathrm{Y}$ ratio to 0.9 and $\boldsymbol{\tau}_{\mathbf{y z}}$ decreased from (.446) to (.432) $\mathrm{MPa}$, when $\mathrm{D} / \mathrm{Y}=0.2$, then increased to (.646) $\mathrm{MPa}$ with increase of $\mathrm{D} / \mathrm{Y}$ ratio from 0.2 to 0.7 . Finally decreased to (.617) $\mathrm{MPa}$, with increase of $\mathrm{D} / \mathrm{Y}$ ratio from 0.7 to 0.9 , and $\tau_{\mathbf{X z}}$ decreased from (.239) to (.028) $\mathrm{MPa}$, when $\mathrm{D} / \mathrm{Y}=0.2$, then increased to (.038) $\mathrm{MPa}$, with increase of $\mathrm{D} / \mathrm{Y}$ ratio from 0.2 to 0.5 , and decreased to (.032) $\mathrm{MPa}$ with increase of $\mathrm{D} / \mathrm{Y}$ ratio from 0.5 to 0.7 , and finally increased to (.356) MPa with increase of $\mathrm{D} / \mathrm{Y}$ ratio from 0.7 to 0.9 .
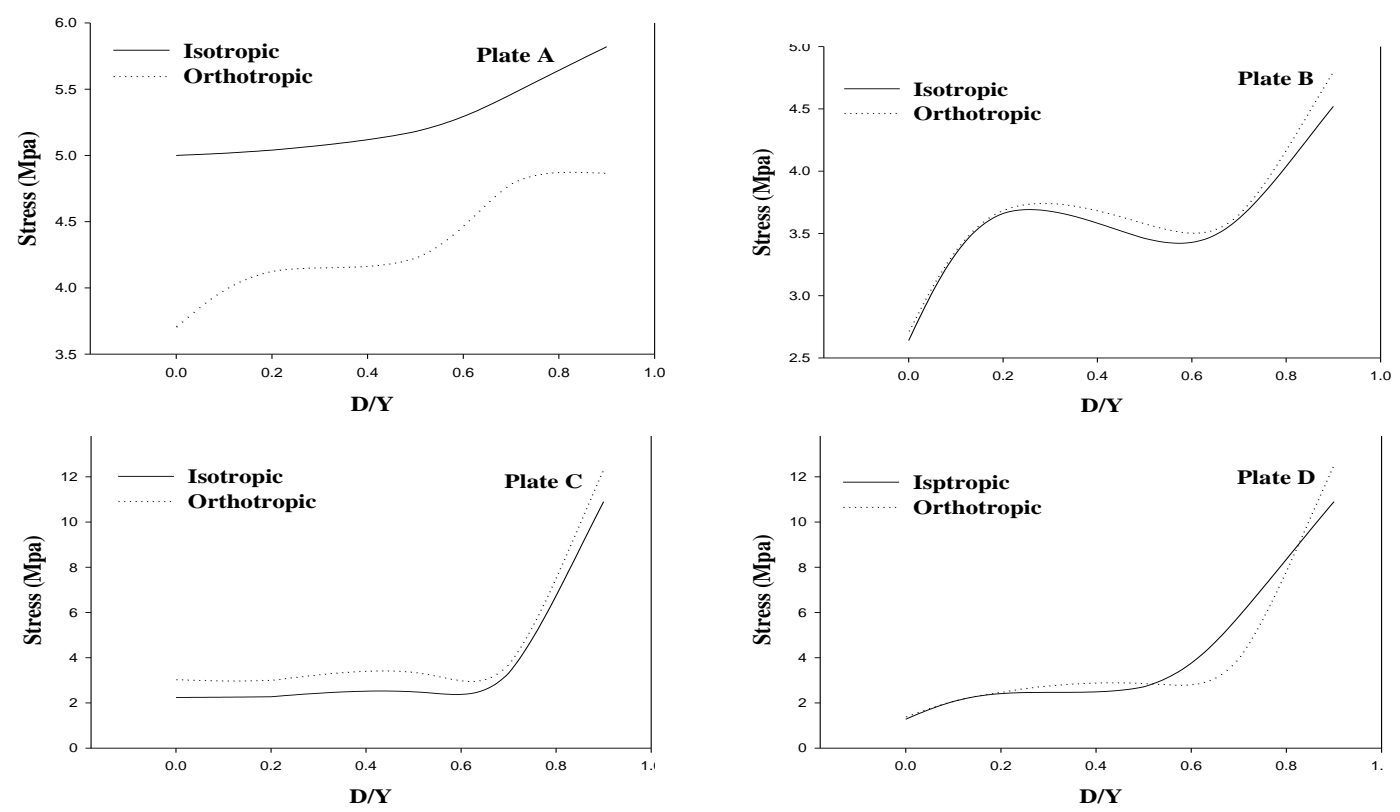

Fig. 25 Effect of hole diameter on $\boldsymbol{\sigma}_{\mathrm{von}}$ in plates (A), (B), (C) and (D) of an isotropic and orthotropic materials 

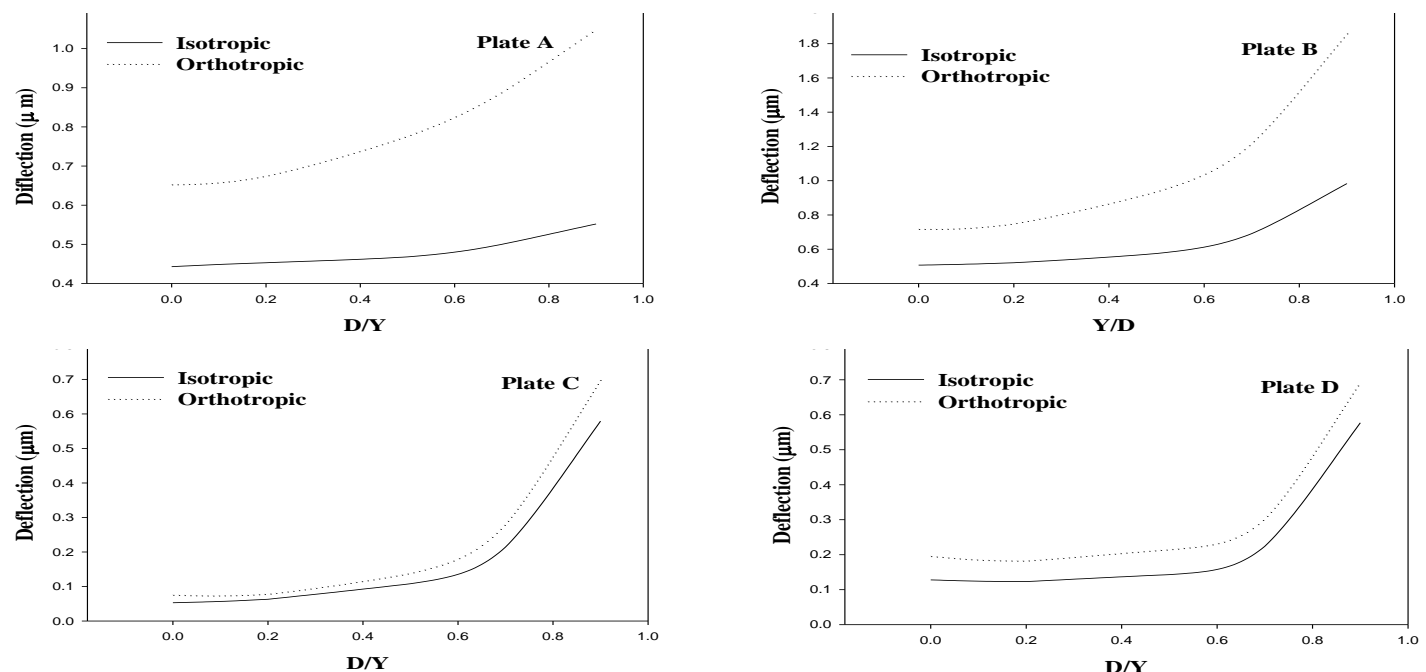

Fig.26 Effect of hole diameter on $\mathbf{U x}$ in plates (A), (B), (C) and (D) of isotropic and orthotropic materials
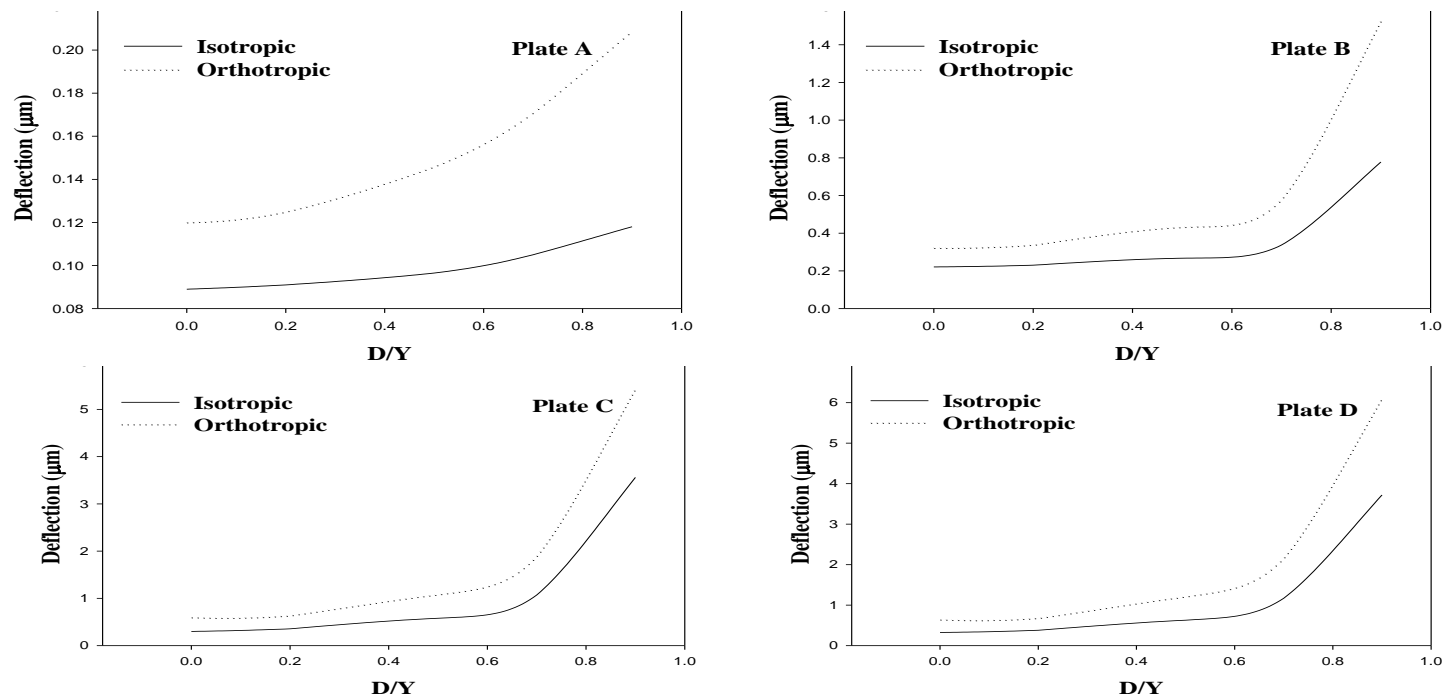

Fig.27 Effect of hole diameter on $\mathbf{U y}$ in plates (A), (B), (C) and (D) of isotropic and orthotropic materials
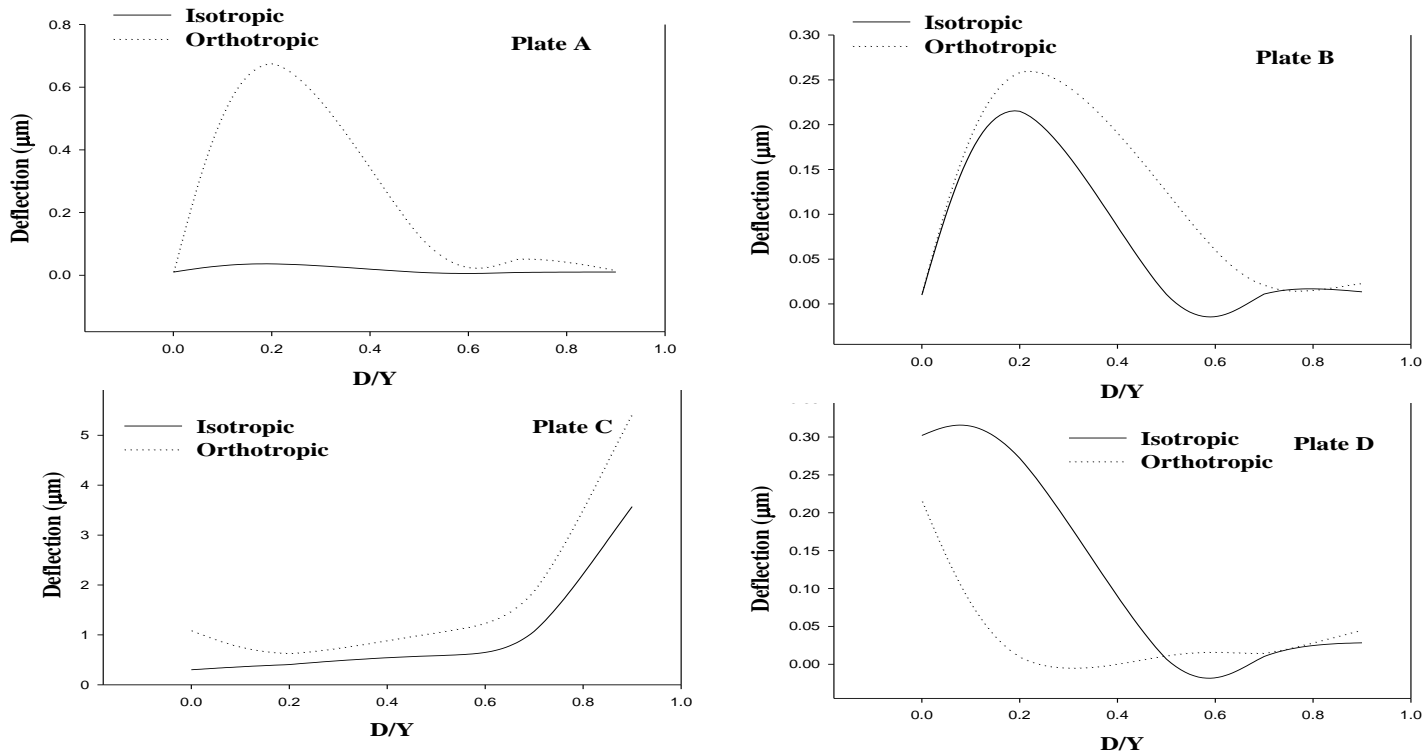

Fig.28 Effect of hole diameter on $\mathbf{~} \mathbf{z}$ in plates (A), (B), (C) and (D) of isotropic and orthotropic materials 
Figure (31), shows the following observations from these results. In the case of orthotropic materials, it can be noticed that, the variation of $\boldsymbol{\tau}_{\mathbf{x y}}$ with respect to $\mathrm{D} / \mathrm{Y}$ is maximum in the four cases of plate. And the variation of $\boldsymbol{\tau}_{\mathbf{y z}}$ with respect to $\mathrm{D} / \mathrm{Y}$ ratio is negligible in the four cases of the plate, and the variation of $\boldsymbol{\tau}_{\mathbf{x z}}$ with respect to $\mathrm{D} / \mathrm{Y}$ ratio is observed: significant in the case of plate (A), and maximum in the case of plate (B), and negligible in the cases of (C) and (D). In the case (A) the value of $\boldsymbol{\tau}_{\mathbf{x y}}$, increased from (1.4) to (1.79) $\mathrm{MPa}$, with increase of $\mathrm{D} / \mathrm{Y}$ ratio to 0.9 . And $\boldsymbol{\tau}_{\mathbf{y z}}$ increased from (.101) to (.239) $\mathrm{MPa}$ increase of $\mathrm{D} / \mathrm{Y}$ ratio from 0.2 to 0.7 , then decreased to (.184) $\mathrm{MPa}$ with increase of $\mathrm{D} / \mathrm{Y}$ ratio from 0.7 to 0.9 and $\tau_{x z}$ increased from (.775) to (1.03) $\mathrm{MPa}$ when $\mathrm{D} / \mathrm{Y}=0.2$, then decreased
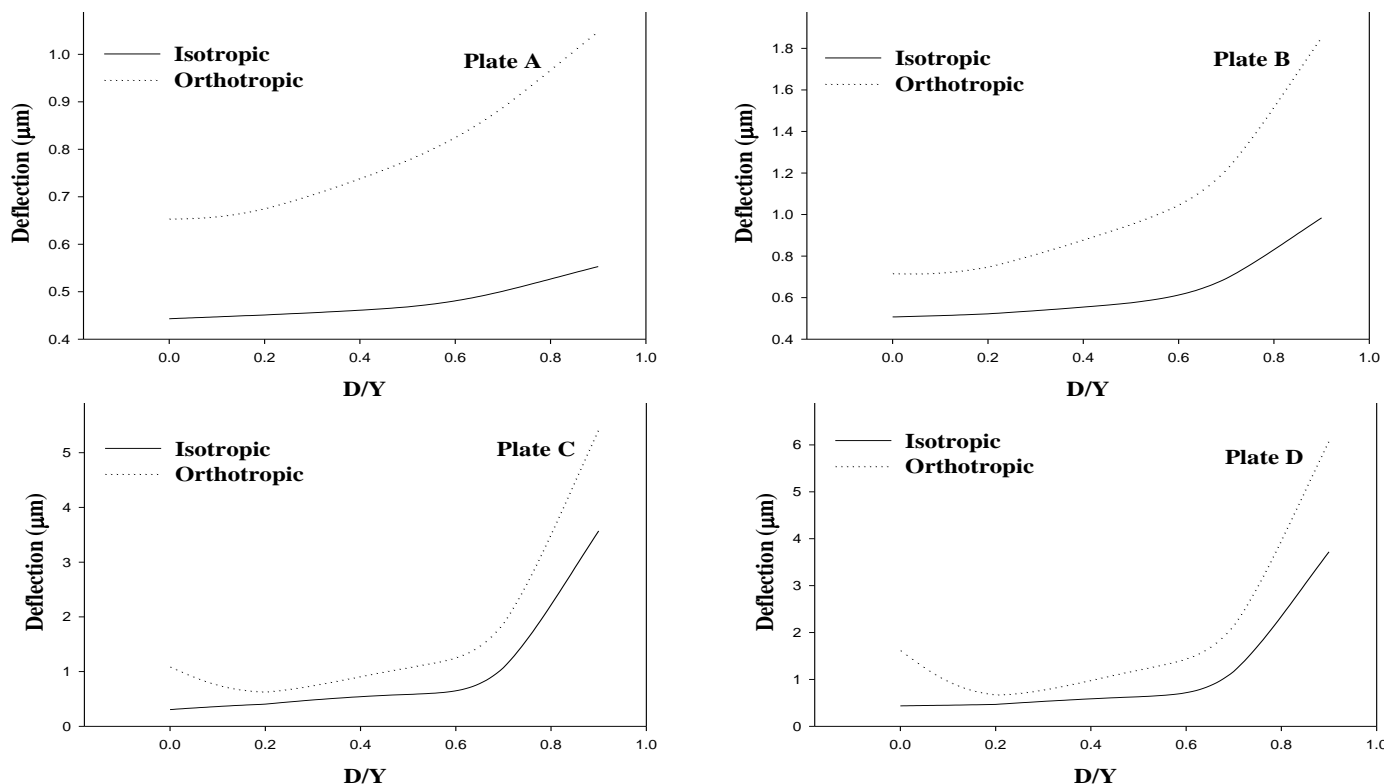

Fig.29 Effect of hole diameter on Usum in plates (A), (B), (C) and (D) of isotropic and orthotropic materials
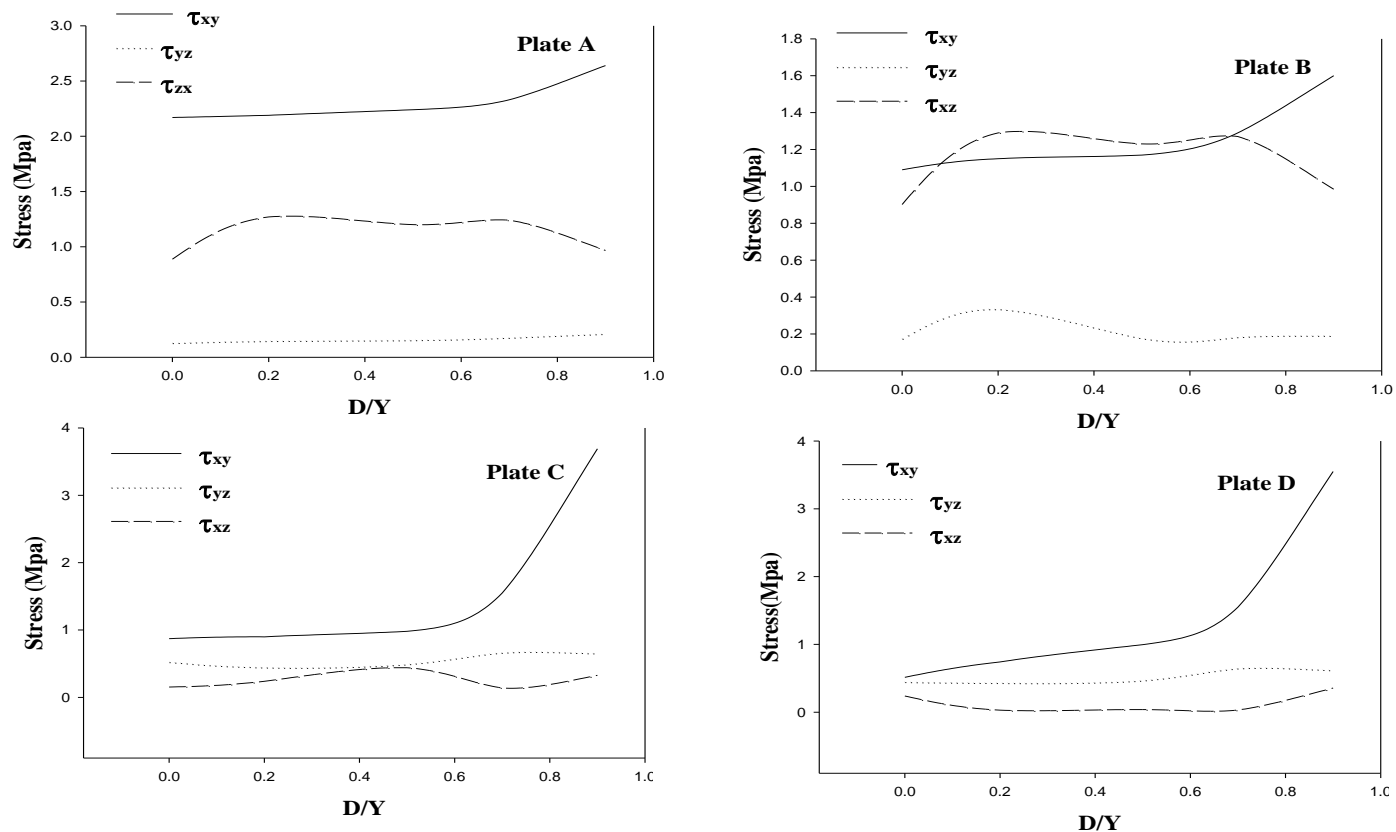

Fig.30 Effect of hole diameter on $\boldsymbol{\tau}_{\mathbf{x y}}, \boldsymbol{\tau}_{\mathbf{y z}}$, and $\boldsymbol{\tau}_{\mathbf{x z}}$ in plates (A), (B),

(C) and (D) of an isotropic material 
to (.869) $\mathrm{MPa}$ with increase of $\mathrm{D} / \mathrm{Y}$ ratio from 0.2 to 0.9 . In the case (B) the value of $\boldsymbol{\tau}_{\mathbf{x y}}$ increased from (.845) to (1.43) $\mathrm{MPa}$, with increase of $\mathrm{D} / \mathrm{Y}$ ratio to 0.9 . In addition, $\boldsymbol{\tau}_{\mathbf{y z}}$ increased from (.125) to (.119) $\mathrm{MPa}$, with increase of $\mathrm{D} / \mathrm{Y}$ ratio from 0.2 to 0.7 . Then decreased to (.137) $\mathrm{MPa}$ with increase of $\mathrm{D} / \mathrm{Y}$ ratio from 0.7 to 0.9 and $\boldsymbol{\tau}_{\mathbf{x z}}$ increased from (.782) to (1.04) $\mathrm{MPa}$ when $\mathrm{D} / \mathrm{Y}=0.2$, then decreased to (.871) $\mathrm{MPa}$ with increase of $\mathrm{D} / \mathrm{Y}$ ratio from 0.2 to 0.9 . In the case (C) the value of $\boldsymbol{\tau}_{\mathbf{x y}}$ increased from (.755) to (3.06) $\mathrm{MPa}$, with increase of $\mathrm{D} / \mathrm{Y}$ ratio to 0.9 . In addition, $\boldsymbol{\tau}_{\mathbf{y z}}$ decreased from (.494) to (.42) MPa, when $\mathrm{D} / \mathrm{Y}=0.2$. Then increased to (.62) $\mathrm{MPa}$, with increase of $\mathrm{D} / \mathrm{Y}$ ratio from 0.2 to 0.7 , then decreased to (.591) $\mathrm{MPa}$ with increase of $\mathrm{D} / \mathrm{Y}$ ratio from 0.7 to 0.9 and $\boldsymbol{\tau}_{\mathbf{x z}}$ decreased from (.12) to (.09) $\mathrm{MPa}$ when $\mathrm{D} / \mathrm{Y}=0.2$, then increased to (.306) $\mathrm{MPa}$ with increase of $\mathrm{D} / \mathrm{Y}$ ratio from 0.2 to 0.9 . In the case (D) the value of $\boldsymbol{\tau}_{\mathbf{x y}}$ increased from (.562) to (3.08) MPa, with increase of $\mathrm{D} / \mathrm{Y}$ ratio to 0.9 . In addition, $\tau_{\mathbf{y z}}$ decreased from (.498) to (.423) MPa when D/Y $=0.2$, then increased to (.63) $\mathrm{MPa}$ with increase of $\mathrm{D} / \mathrm{Y}$ ratio from 0.2 to 0.7 . In addition, decreased to (.604) $\mathrm{MPa}$ with increase of $\mathrm{D} / \mathrm{Y}$ ratio from 0.7 to 0.9 and $\boldsymbol{\tau}_{\mathbf{x z}}$ decreased from (.066) to (.026) $\mathrm{MPa}$ when $\mathrm{D} / \mathrm{Y}=0.2$, then increased to (.329) $\mathrm{MPa}$ with increase of $\mathrm{D} / \mathrm{Y}$ ratio from 0.2 to 0.9 .
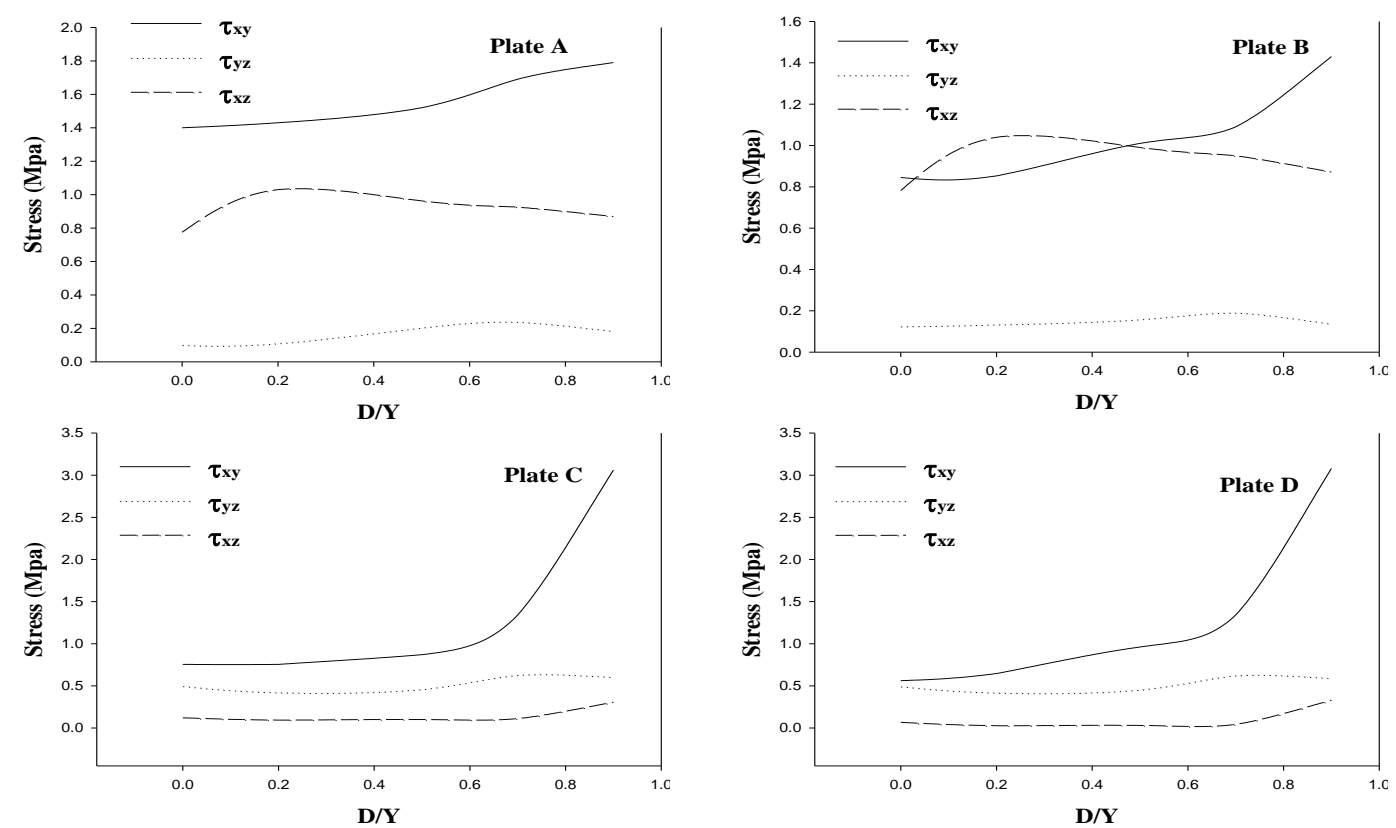

Fig.31 Effect of hole diameter on $\boldsymbol{\tau}_{\mathbf{x y}}, \boldsymbol{\tau}_{\mathbf{y z}}$, and $\boldsymbol{\tau}_{\mathbf{x z}}$ in plates (A), (B),

(C) and (D) of an orthotropic material

\section{Conclusion}

The variation of the stresses $\left(\sigma_{\mathrm{x}}\right)$ with respect to $\mathrm{D} / \mathrm{Y}$ ratio was clearly observed in orthotropic plates, compared to isotropic plates for all boundary conditions. For (a) and (b), the variation of the stresses $\left(\sigma_{\mathrm{y}}\right)$ with respect to $\mathrm{D} / \mathrm{Y}$ ratio is small when considered orthotropic material as compared to that when isotropic, whereas on the same variants is more for plate (D). When ( $\mathrm{D} / \mathrm{Y}=0.7)$, the variations are the same. After that, it increases for plate $(C)$ when isotropic. The variation is observed of the stresses $\left(\sigma_{\mathrm{z}}\right)$, with respect to $\mathrm{D} / \mathrm{Y}$ ratio, is less than in when orthotropic than that when isotropic for all boundary conditions, especially when $\mathrm{D} / \mathrm{Y}$ becomes 0.7 . When orthotropic, the variation of the stress $\sigma_{\mathrm{Von}}$ for $(\mathrm{A})$ 
and $(\mathrm{C})$ is less than that when isotropic especially when $\mathrm{D} / \mathrm{Y}$ becomes 0.7 . After that, the two materials coincide at the same path for both (B) and (D).

The variation of the deflections $(\mathrm{Ux})$, ( $\mathrm{Uy}$ ) with respect to $\mathrm{D} / \mathrm{Y}$ ratio was clearly observed in orthotropic plates as compared to isotropic plates for all boundary conditions. For all cases, developed maximum deflection in $\mathrm{x}$ - direction $(\mathrm{Ux})$, whereas the minimum deflection $(\mathrm{Ux})$ was developed in plate $(\mathrm{A})$. Plate $(\mathrm{D})$ developed maximum deflection in $\mathrm{y}$ direction ( $\mathrm{Uy}$ ) and plate (A) developed the minimum. For all, the deflections in both directions increased at $\mathrm{D} / \mathrm{Y}=0.7$.

The variation observed of the deflection $(\mathrm{Uz})$ for orthotropic, with respect to $\mathrm{D} / \mathrm{Y}$ ratio, is greater than that for isotropic plates in all boundary conditions except (D). For both materials, the maximum deflection in $\mathrm{z}$ - direction is observed in plate $(\mathrm{C})$. For all materials, plates (A) and (B) developed increasing in deflection (Uz) with $\mathrm{D} / \mathrm{Y}$ ratio for the first time, then the deflection decreased. In the case of plate (D) the deflection (Uz) decreased with increasing of $\mathrm{D} / \mathrm{Y}$ ratio. But in case of plate $(\mathrm{D}),(\mathrm{Uz})$ the decreased with increase of $\mathrm{D} / \mathrm{Y}$. The variation of the deflections (Usum), with respect to $\mathrm{D} / \mathrm{Y}$ ratio, in orthotropic plates is more than that of isotropic plates for all boundary conditions. It is also observed that the trend of variation of deflection (Usum) with $\mathrm{D} / \mathrm{Y}$ ratio is almost the same for all materials for respective boundary conditions. For plate (A) the maximum shear stress was occurred in the $\mathrm{XY}$ plane, $\left(\tau_{\mathrm{xy}}\right)$, and the minimum shear stress was occurred in $\mathrm{YZ}$ plane, $\left(\tau_{\mathrm{yz}}\right)$. The shear stress in $\mathrm{XZ}$ plane $\left(\tau_{\mathrm{xz}}\right)$ varied significantly with respect to $\mathrm{D} / \mathrm{Y}$ ratio for both materials. For plates (B), (C) and (D), the maximum shear stress was occurred in the XY plane $\left(\tau_{x y}\right)$ and the minimum shear stress occur in $\mathrm{XZ}$ plane $\left(\tau_{\mathrm{xz}}\right)$. The shear stress in $\mathrm{YZ}$ plane $\left(\tau_{\mathrm{yz}}\right)$ varied significantly with respect to $\mathrm{D} / \mathrm{Y}$ ratio for both materials. It is also observed that the variation of SCF for all stresses with $\mathrm{D} / \mathrm{Y}$ ratio; highly depends on the elastic constants and differs with material to material. For all materials, the stresses were occurred at maximum values in plates(C) and (D) and at minimums in plates (A) and (B), Hence the SCF for $\sigma_{\mathrm{x}}$ and $\sigma_{\mathrm{y}}$ plays an important role in design of plates (C) and (D) and a minor role in the design of plates (A) and (B).

\section{REFERENCES}

1. X.J., Cheng, Wu. A higher order theory for plane stress conditions of laminates consisting of isotropic layers. Journal of Applied Mechanics 66 ,95-100, 1999.

2. C., J., Hsu, Chen. The stress intensity factors of slightly undulating interface cracks of bimaterials. International Journal of Fracture 80, 277-293, 1996.

3. X,.F., Wang, Hasebe, N. Bending of a thin plate containing a rigid inclusion and a crack. Engineering Analysis with Boundary Elements 24, 145-153, 2000.

4. R. A. Chaudhuri, Stress concentration around a part through hole weakening laminated plate, Computers \& Structures, vol. 27(5), pp. 601-609, 1987.

5. H., Y., Kohno, Ishikawa. Analysis of stress singularities at the corner point of square hole and rigid square inclusion in elastic plates by conformal mapping. International Journal of Engineering Science 31 (8), 1197-1213, 1993.

6. T. K. Paul, and K. M. Rao, Stress analysis in circular holes in FRP laminates under transverse load, Computers \& Structures, vol. 33(4), pp. 929-935, 1989. 
7. T. K. Paul, and K. M. Rao, Finite element evaluation of stress concentration factor of thick laminated plates under transverse loading, Computers \& Structures, vol. 48(2), pp. 311-317, 1993.

8. B. P. Shastry, and G. V. Raj Effect of fiber orientation on stress concentration in a unidirectional tensile laminate of finite width with a central circular hole, Fiber Science and Technology, vol. 10, pp. 151- 154, 1997.

9. X. Xiwu, S. Liangxin, and F. Xuqi, Stress concentration of finite composite laminates with elliptical hole, Computers \& Structures, vol.57(1), pp. 29-34, 1995.

10. X. Xiwu, S. Liangxin, and F. Xuqi, Stress concentration of finite composite laminates weakened by multiple elliptical holes, International Journal of Solids Structures, vol. 32(20), pp. 3001-3014, 1995.

11. T. Iwaki, Stress concentrations in a plate with two unequal circular holes, International Journal of Engineering Sciences, vol. 18(8), pp. 1077-1090, 1980.

12. V. Ukadgaonker, and D. K. Rao, A general solution for stress around holes in symmetric laminates under plane loading, Composite Structure, vol.49, pp. 339-354, 2000.

13. K. Ting, K. T. Chen, and W. S. Yang, Stress analysis of the multiple circular holes with the rhombic array using alternating method, International Journal of Pressure Vessels and Piping, vol. 76, pp. 503- 514, 1999.

14. E., Pan, Yang, B., Cai, G., Yuan, F.G. Stress analyses around holes in composite laminates using boundary element method. Journal of Engineering Analysis with Boundary Elements 25, 31-40, 2001.

15. S. G. Lekhnitskii, Anisotropic Plates. Gordon and Breach, New York (1968).

16. Help of The ANSYS Program V12.0. (2010). 